

\section{Lunar Terrain Mapping and Relative-Roughness Analysis}

By LAWRENCE C. ROWAN, JOHN F. MCCAULEY, and ESTHER A. HOLM C O N T R I B U T I O N S T O A S T R O G E O L O Y

GEOLOGICAL SURVEY PROFESSIONAL PAPER 599-G

Prepared on behalf of the

National Aeronautics and Space Administration 


\section{UNITED STATES DEPARTMENT OF THE INTERIOR}

ROGERS C. B. MORTON, Secretary

\section{GEOLOGICAL SURVEY}

William T. Pecora, Director

Library of Congress catalog-card No. 74-609839

For sale by the Superintendent of Documents, U.S. Government Printing Office Washington, D.C. 20402 - Price 45 cents (paper cover) 


\section{CONTENTS}

Abstract

Introduction

Scope and purpose

Previous work and sources of data

Acknowledgments

Lunar terrain mapping

$1: 2,000,000$-scale terrain mapping

1:1,000,000-scale terrain mapping

Visual telescopic terrain mapping

Slope-measuring program

Photoclinometry

Limitations of earth-based photoclinometry

Relative relief

\begin{tabular}{r|c} 
Page & Statistical analysis \\
1 & Sampling procedure \\
1 & Slope-frequency distribution functions \\
3 & Slope-component statistics \\
3 & Relative-roughness parameters \\
3 & Extrapolation techniques \\
5 & Applications to spacecraft targeting \\
5 & Ranger \\
8 & Surveyor \\
9 & Lunar Orbiter \\
9 & Summary \\
11 & Selected references \\
12 & Lunar geologic map references
\end{tabular}

Page G13

13

14

19

22

24

26

26

26

26

27

27

28

\section{ILLUSTRATIONS}

1. Photograph showing the extent of the lunar terrain study area

2. Map showing terrain of part of the Sinus Medii area, mapped at a scale of 1:2,000,000

3. Map showing terrain of part of the Sinus Medii area, mapped at a scale of $1: 1,000,000$

4. Map of lunar terrain prepared by visual telescopic observation.

5. Diagram showing the geometry of the lunar photometric function

6. Diagram showing the geometric relations between selenographic longitude and east-west slope components

7. Graph showing idealized microphotometer traverse on the lunar surface and the standard curves for different relative albedo units

8-12. Diagrams showing:

8. Locations of 51 slope-component sample areas in the lunar equatorial zone

9. Schematic topographic profiles

10. Cumulative slope-component frequency distribution curves for six terrains units

11. Arithmetic probability plot of slope-component percentile values for typical samples

12. Algebraic slope-component frequency distribution curves

for three typical lunar terrain samples

13. Photograph showing nature and extent of different slope-component populations of the Gambart sample area

14. Diagram showing algebraic slope-component

frequency distribution curves for the Gambart sample area

15. Diagram showing schematic topographic profiles

16. Photograph showing boundaries of the slope-component samples and the morphologic types of the Schröter F sample area

17-21. Diagrams showing:

17. Cumulative slope-frequency distribution curves for rough terrestrial terrain

18. Plot of the algebraic standard deviation versus the absolute arithmetic mean for the 51 slope-component sample areas

19. Relative-relief frequency histograms

20. Extrapolation of median slope to the 1-meter scale from telescopic data for mare terrain

21. Algebraic slope-component frequency distribution curve and statistical parameters for Ranger VII photograph $\mathrm{P}_{3}-979$ of an area in Mare Cognitum

22. Southern part of Marius Hills area near crater Reiner

23. Southern Sinus Medii area

24. Intermare area northwest of Fra Mauro 
FIGUREs 22-29. Representative lunar terrain units in-Continued

25. Area northwest of crater Ptolemaeus

26. Area between craters Ptolemaeus and Hipparchus

27. Appennine Mountains, south of Mare Imbrium _

28. Aristillus area in Mare Imbrium …_

29. Albategnius area -..._-__-

\section{TABLES}

Table 1. Terrain units of the lunar equatorial belt

2. Significant statistical slope-component parameters and the terrain units

3. Slope-component statistics for sample areas in the multimorphic Schröter F area

4. Limiting relative-roughness values for major terrain units in the lunar equatorial zone 


\title{
LUNAR TERRAIN MAPPING AND RELATIVE-ROUGHNESS
} ANALYSIS

\author{
By Lawrence C. Rowan, John F. MCCaUley, and Esther A. Holm
}

\begin{abstract}
ABSTRAGT
Terrain maps of the equatorial zone (long $70^{\circ}$ E. $-70^{\circ} \mathrm{W}$. and lat $10^{\circ} \mathrm{N}-10^{\circ} \mathrm{S}$.) were prepared at scales of $1: 2,000,000$ and $1: 1,000,000$ to classify lunar terrain with respect to roughness and to provide a basis for selecting sites for Surveyor and Apollo landings as well as for Ranger and Lunar Orbiter photographs. The techniques that were developed as a result of this effort can be applied to future planetary exploration.

By using the best available earth-based observational data and photographs 1:1,000,000-scale and U.S. Geological Survey lunar geologic maps and U.S. Air Force Aeronautical Chart and Information Center LAC charts, Iunar terrain was described by qualitative and quantitative methods and divided into four fundamental classes: maria, terrae, craters, and linear features. Some 35 subdivisions were defined and mapped throughout the equatorial zone, and, in addition, most of the map units were illustrated by photographs.

The terrain types were analyzed quantitatively to characterize and order their relative-roughness characteristics. Approximately 150,000 east-west slope measurements made by a photometric technique (photoclinometry) in 51 sample areas indicate that algebraic slope-frequency distributions are Gaussian, and so arithmetic means and standard deviations accurately describe the distribution functions. The algebraic slope-component frequency distributions are particularly useful for rapidly determining relative roughness of terrain.

The statistical parameters that best describe relative roughness are the absolute arithmetic mean, the algebraic standard deviation, and the percentage of slope reversal. Statistically derived relative-relief parameters are desirable supplementary measures of relative roughness in the terrae. Extrapolation of relative roughness for the maria was demonstrated using Ranger VII slope-component data and regional maria slope data, as well as the data reported here. It appears that, for some morphologically homogeneous mare areas, relative roughness can be extrapolated to the large scales from measurements at small scales.
\end{abstract}

\section{INTRODUCTION SCOPE AND PURPOSE}

In October 1963, the U.S. Geological Survey began, on behalf of the National Aeronautics and Space Administration (contract No. W-11,775), a program of terrain studies of the lunar equatorial zone (lat $10^{\circ} \mathrm{N} .-10^{\circ} \mathrm{S}$., long $70^{\circ}$ E. $-70^{\circ} \mathrm{W}$.), the area most suitable from an engineering standpoint for early Apollo manned landings (fig. 1). These studies complemented the 1:1,000,000-scale lunar geological mapping program and aided in selection of targets for Ranger VII and VIII, Lunar Orbiter, and Surveyor I missions.

The principal objectives of the terrain analysis program were (1) to examine the roughness characteristics of the existing lunar geologic map units, (2) to redefine and regroup these geologic units into mappable terrain or morphologic units without regard to their stratigraphic position, (3) to characterize the relative roughness of these terrain units by means of simple statistical expressions and to depict their distribution in a series of terrain maps which could be used for mission planning, (4) to study the smoothest parts of the lunar equatorial belt visually at the telescope to evaluate their relative suitability as landing areas for Surveyor and Apollo spacecraft and thereby further narrow the area to be photographed by Lunar Orbiter spacecraft, and (5) to refine and automate existing photometric slope-measuring techniques for the purpose of generating quantitative slope data for statistical analysis.

Many reports were prepared to meet flight schedules of the unmanned Lunar Orbiter and Surveyor programs; most have not been formally published. Some of these, released in open files by the U.S. Geological Survey, are listed under "Selected references." The integration of these preflight support studies into the mission plans of the early Surveyor and Orbiter experiments was an element in the overall success of the missions.

The purpose of this paper is (1) to summarize lunar terrain mapping techniques described in these 


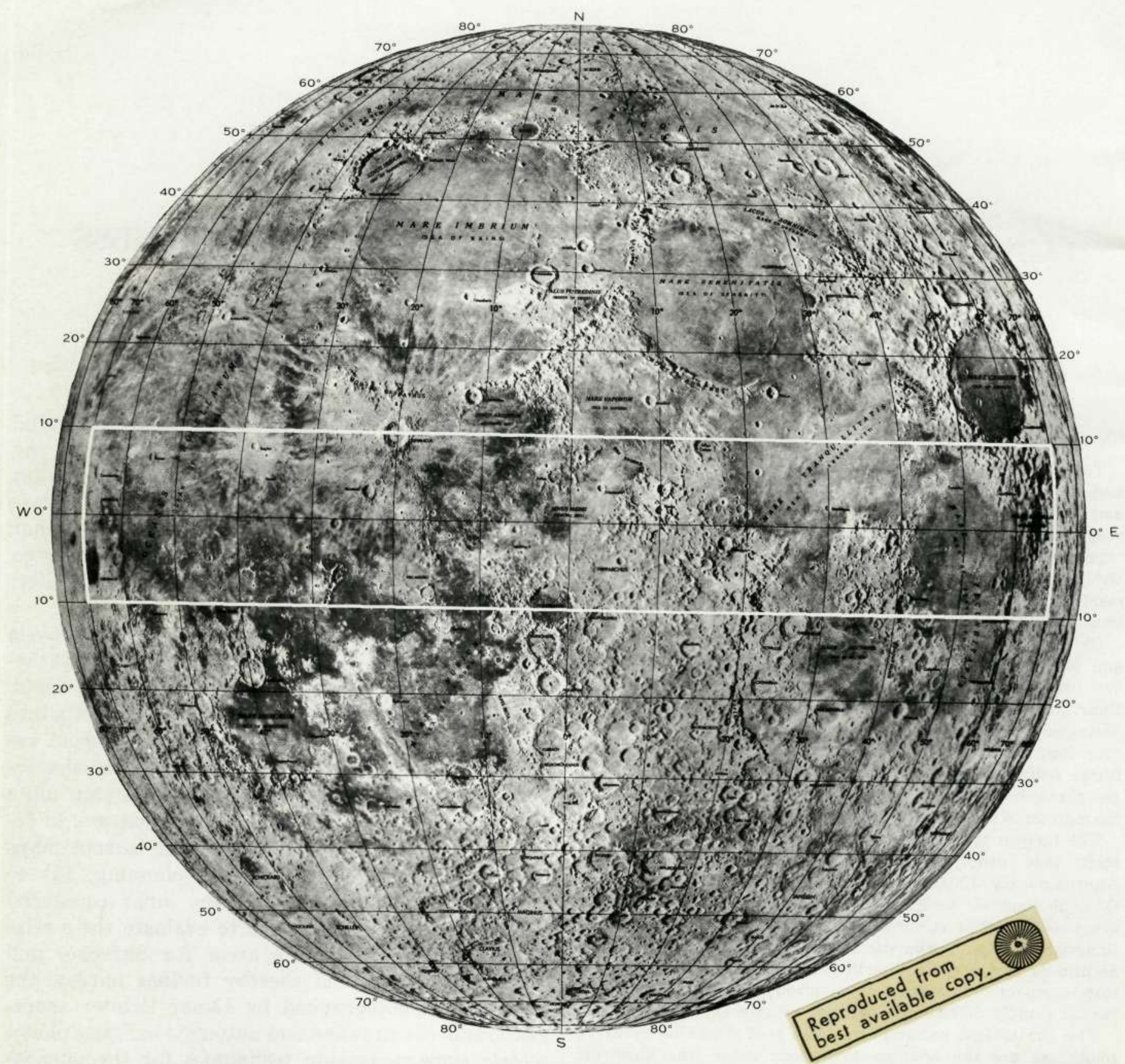

Figure 1.-U.S. Air Force Chart and Information Center photomosaic showing the extent of the lunar terrain study area.

mostly unpublished sources, (2) to describe the photometric method used to extract slope data from telescopic photographs, (3) to describe the various statistical parameters that were applied to the slope data to establish relative roughness, and (4) to review, briefly, the major applications to targeting of the unmanned lunar probes, particularly Surveyor I and the early Lunar Orbiters. Since completion of this work, the high-resolution data from the many successful probes have rendered most of the tele- scopic measurements and maps obsolete. For this reason emphasis is placed on the techniques and methodology developed through mid-1966, time of the first Lunar Orbiter flight, rather than on specific results. The techniques remain applicable to higher resolution terrain analyses of the moon and other terrestrial planets. The slope measurements and statistical classifications are currently in various stages of refinement and engineering application because of a continuously improving stream of data. 


\section{PREVIOUS WORK AND SOURCES OF DATA}

An antecedent of the program described here was the pioneering work of Hackman and Mason (1961). Their report consists of the following: (1) A description of physiographic divisions of the moon, which divides surfaces features according to "extent of preservation, type of modification, type of surface material, elevations, slopes and structural disturbances," (2) a generalized photogeologic map of the moon, which classifies surface materials into premaria, maria, and postmaria ages, (3) a map showing the distribution of lunar rays, which are interpreted as ballistic ejecta from the larger impact craters, and (4) a brief interpretative text and a unit-by-unit discussion of the predicted landing, mobility, and construction characteristics within each of the physiographic divisions. The terrain study described here is thus an extension of Hackman and Mason's work and represents a similar application of geologic methodology to the engineering aspects of planetary exploration, particularly the problem of landing-site selection. Additional terrain studies directed more towards surface mobility problems have since been undertaken by Rozema (1968).

Much of the topographic and geologic data utilized in the present study was produced by two systematic 1:1,000,000-scale telescopic mapping programs: (1) the U.S. Geological Survey lunar geologic mapping program, summarized by Wilhelms (1970) and (2) the 1:1,000,000-scale topographic mapping program of the U.S. Air Force Aeronautical Chart and Information Center. Additional sources of raw data included (1) published and unpublished lunar photographs from Mount Wilson, Lick, McDonald, Pic du Midi, and Catalina Observatories and (2) visual studies of selected parts of the lunar equatorial belt at the U.S. Geological Survey 30 -inch reflecting telescope near Flagstaff, Ariz.; the Kitt Peak National Observatory 60 -inch reflecting telescope and the McMath solar telescope, both west of Tucson, Ariz.; and the Lick Observatory 36 -inch refracting telescope, Mount Hamilton, Calif.

Quantitative topographic data consisted of (1) east-west slope-component measurements obtained by photometric techniques developed by the U.S. Geological Survey (Wilhelms; 1964; McCauley, 1964; Rowan and McCauley, 1966) and (2) relative-relief measurements made by the shadow technique (Kopal, 1962) and furnished by the U.S. Air Force Aeronautical Chart and Information Center, St. Louis, Mo.

\section{ACKNOWLEDGMENTS}

The authors wish to acknowledge the following individuals who contributed to the program: Eugene M. Shoemaker, for his early encouragement and advice in the work of refining existing slope-measuring techniques; Harold Masursky, for his work in training telescopic observers at the Lick 36-inch telescope; Elliot Morris, Henry E. Holt, and Alan Filice, for helping to prepare and present to the National Aeronautics and Space Administration the final recommendations of the Surveyor I landing site; Peter E. Krauss, Ralph Eicher, and Fred B. Sower, for their help in automating the photometric slope-measuring technique; and Anne Kelly, Sidney L. Dowd III, James Hart, and John R. Running, for their overall technical support, which greatly facilitated the meeting of an almost continuous array of deadlines imposed by flight schedules. Special thanks are extended to Jerry Harbour for his previously uncited contributions to the first terrain studies report in 1964 .

\section{LUNAR TERRAIN MAPPING}

Terrain maps generally portray the areal distribution patterns of relatively homogeneous land-surface forms, such as plains, tablelands, hills, and mountains, without genetic implication. Examples of this type of map, adapted from the work of Hammond (1964), are sheets $61-64$ of the National Atlas (U.S. Geol. Survey, 1968). Large-scale terrain maps, such as those prepared by the Department of the Army (Chief of Engineers, 1958), usually serve a specific practical purpose, such as trafficability analysis. The terrain, or land-surface form, map is distinct from the physiographic map (for example, sheet 59, Natl. Atlas), which attempts to provide an understanding of landform genesis, and from geologic and tectonic maps, wherein the fundamental classification is according to geologic age or the role of a body of rocks in the tectonic history of a region.

The lunar terrain maps prepared during this study are special-purpose landform maps that depict varying degrees of suitability for both unmanned and manned landings. They convey no stratigraphic or genetic information; however, because the Geological Survey's 1:1,000,000-scale lunar geologic map series was used extensively in the compilation of the terrain maps, the terrain unit boundaries generally coincide with stratigraphic unit boundaries, particularly where a given stratigraphic unit is characterized by unique terrain characteristics. Generally, terrain unit boundaries depart from stratigraphic contacts where morphologic expression on two or more stratigraphic units is similar or where the morphologic properties of a stratigraphic unit vary laterally, as around the younger multiring basins. 


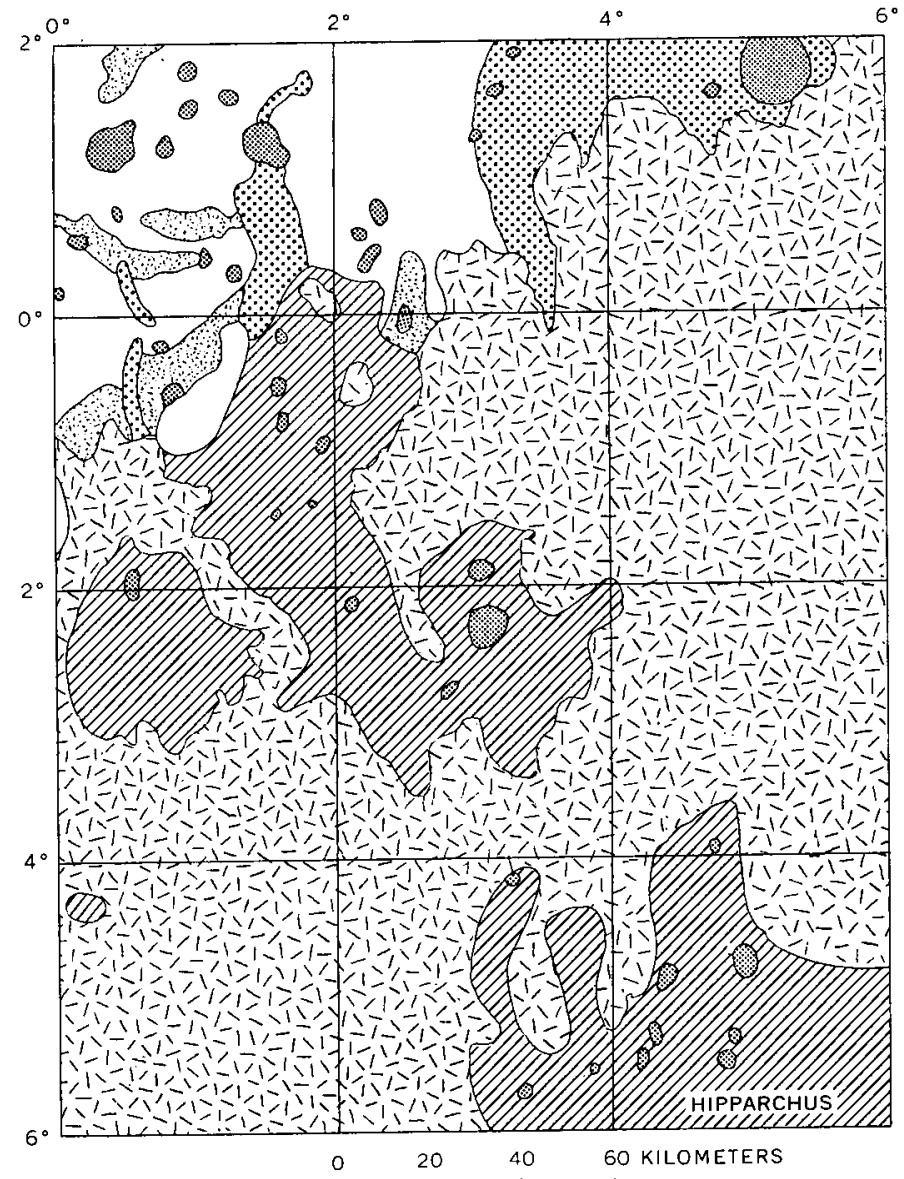

EXPLANATION

Tedian slope frequency ranges from zero (no resolvable relief) for small areas to $1.5^{\circ}$ as determined by photometric techniques. Generally consists of the darker parts of the maria

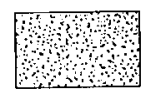

Median slope frequency ranges from zero (no resolvable relief) for small areas to $1.5^{\circ}$ as determined by photometric techniques. Generally consists of the lighter parts of the maria and ray-cover mare areas. Visual

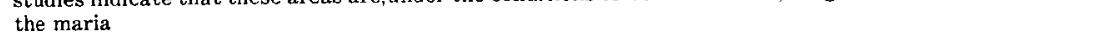

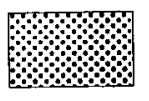

Median slope frequency ranges from $1^{\circ}$ to $2^{\circ}$, as determined by photometric techniques. Consists of mare areas that show numerous structural elements such as sinuous ridges, domes, rilles, or chain craters which contribute to an undulating, uneven topography

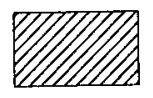

Median slope frequency, as determined by photometric techniques, ranges from $1.5^{\circ}$ to $2.5^{\circ}$. Consists generally of relatively smooth basins occupying the floors of the largest craters

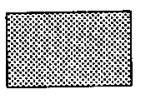

Median to $6^{\circ}$. Consists of individual craters superimposed on smoother, surfaces. Includes both the crater floor, walls, and rim deposits to a distance of approximately one crater radius

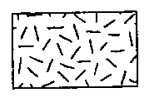

Median slope frequency, as determined from shadow progression, and photometric techniques, ranges from $3^{\circ}$ primarily of a complex sequence of overlapping craters an of the interior walls of individual crater is $37^{\circ}$

FIGURE 2.-Terrain of part of the Sinus Medii area, mapped at 1:2,000,000 scale; units described by slope-component statistics (after McCauley, 1964, p. 27-30). 
1:2,000,000-SCALE TERRAIN MAPPING

The first effort at lunar terrain classification resulted in a six-unit 1:2,000,000-scale map of the area from long $15^{\circ}$ E. $-60^{\circ} \mathrm{W}$, and from lat $10^{\circ} \mathrm{N} \cdot-10^{\circ} \mathrm{S}$. (McCauley, 1964). The central part of this map is reproduced in figure 2 . The six terrain units were defined and ranked on the basis of median slope values (McCauley, 1965), which were calculated from some 40,000 measurements made for slope elements about $0.75 \mathrm{~km}$ in length. In order of decreasing roughness, the units are as follows: (1) Rugged terra, consisting mostly of closely spaced hills and ridges, degraded craters, and crater remnants with collective median slope values from $3^{\circ}$ to as much as $8^{\circ}$. (2) Rim, wall, and floor deposits of large fresh craters. Median slope values in this unit range from $2^{\circ}$ to $6^{\circ}$, but slopes on interior walls may be as much as $30^{\circ}$. (3) The relatively smooth-appearing floors of the large circular basins in the terrae. These materials are higher in albedo than most of the material in the more extensive mare basins, but are similar otherwise in their telescopic properties; median slope values range from about $1.5^{\circ}$ to $2.5^{\circ}$. (4) Ridges, domes, and rilles in the maria; these areas have median slope values from about $1^{\circ}$ to $2^{\circ}$. (5) Ray-covered mare surfaces; these areas typically surround large freshappearing craters such as Kepler and Copernicus and can be traced radially from the parent crater for distances of 10-20 crater diameters. They do not exhibit, at average telescopic resolution, any greater telescopically measurable roughness than the nonrayed parts of the maria. Visual studies, however, indicate that at very low angles of illumination the ray-covered mare areas appear to be somewhat rougher than nonrayed mare areas. (6) Nonrayed maria; these areas generally show little or no resolvable relief, and median slope values are consistently less than $1.5^{\circ}$ in the intercrater areas.

Prior to this terrain categorization it was not clear to most lunar exploration planners that the rayed parts of the maria are rougher than the nonrayed areas or that the floors of the terra basins are measurably rougher than the maria. Demonstration of the greater roughness of these units led to the general realization that the nonrayed parts of the maria should be examined first by unmanned spacecraft.

1:1,000,000-SCALE TERRAIN MAPPING

During compilation of the 1:2,000,000-scale terrain map, it became apparent that a more detailed map of the equatorial zone would be needed for both Surveyor and Lunar Orbiter site-selection studies, particularly in complex areas. Compilation of a more detailed map at the 1:1,000,000 scale became feasible with the later acquisition of some 65 photographs taken in 1964 at the 120-inch telescope at Lick Observatory. The resolution of these photographs is generally better by a factor of two than previously available photographs (Kuiper, 1960, 1961; Whitaker and others, 1963). Continued refinements in available geologic maps and topographic charts also facilitated 1:1,000,000-scale terrain mapping.

Figure 3 shows part of one of the six 1:1,000,000scale sheets that cover the area from lat $10^{\circ} \mathrm{N}$. to $10^{\circ}$ S. and from long $60^{\circ} \mathrm{E}$. to $60^{\circ} \mathrm{W}$. Table 1 gives descriptions for each unit, and figures 22-29 show telescopic photographs of most of the terrain units. The $1: 1,000,000$-scale terrain classification is based on the recognition of four fundamentally different types of surface forms: (1) mare, (2) terra, (3) craters, and (4) linear features such as ridges, rilles, rays, escarpments, and mare domes. These four morphologic types are in turn divided into related variants.

TABLE 1.-Terrain units of the lunar equatorial belt

I-MARE :

I-A Mare, smooth plains mostly in and around depressed parts of large circular basins.

I-B Mare, dark, smooth plains mostly near margins of large circular basins and along west edge of Oceanus Procellarum.

II-TERRA :

II-A Terra, smooth plains of intermediate albedo with abundant $\approx 1-\mathrm{km}$ craters in terra basins.

II-B Terra, gently rolling to hummocky areas.

II-C Terra, hummocky to moderately blocky areas.

II-D Terra, rough, high blocky areas with deep intervening linear troughs; mostly marginal to south rim of Mare Imbrium.

\section{III-CRATERS :}

III-A Topographically sharp well-formed craters with or without associated bright rays:

III-A-1 Wall (interior), undifferentiated:

III-A-1a Steeply sloping, rough terraced or scalloped walls or detached blocks of wall material.

III-A-1b* Wall, moderately smooth but steeply sloping.

III-A-2 Floor, undifferentiated:

III-A-2a* Floor, smooth plains with little local relief, generally of limited extent.

III-A-2b Floor, hummocky to hilly, rolling topography.

III-A-2c Peaks, generally at or near the center of the floor; rough steeply sloping flanks.

III-A-3 Rim, undifferentiated:

III-A-3a* Rim, rough, hummocky or with concentric troughs and ridges, generally proximal to the rim crest.

III-A-3b* Rim, topography consisting of radial ridges and troughs, distal to hummocky area on rim.

III-B Modified craters, generally of subdued form:

*See footnote at end of table. 
TABLE 1.-Terrain units of the lunar equatorial belt-Cont. III-CRATERS-Continued

III-B-1 Wall (interior), undifferentiated, but generally smooth.

III-B-2 Floor, undifferentiated:

III-B-2a* Floor, smooth areas generally within large markedly deformed craters on terra.

III-B-2b* Floor, rough; marked by blocks and irregular terraces; hummocky.

III-B-2c* Peaks, centrally located; height above crater floor is generally less than that of III-A-2c peaks.

III-B-3* Rim, subdued rolling to hummocky topography; around small craters, this topography cannot be fully resolved.

III-C Crater fields and craters $2-10 \mathrm{~km}$ in diameter.

\section{IV-LINEAR FEATURES :}

IV-A Ridges, both linear and sinuous, located within the mare.

IV-B Domes, some have small summit craters barely resolvable at $1-\mathrm{km}$ resolution; some domes appear rough textured at the limit of telescopic resolution.

IV-C Rilles (rimae) :

IV-C-1 Rilles, linear, occur in both mare and terra; generally have sharply defined steeply sloping interior walls.

$\because \mathrm{IV}-\mathrm{C}-2^{*}$ Rilles, sinuous; generally occur in terra but also along mare margins; commonly originate in crater; some terminate in small bifurcating rilles.

IV D Plateaus, smooth to gently.rolling surfaces, bounded by escarpments; generally within mare.

IV-E* Escarpments (rupes).

$\therefore$ IV-F* Troughs.

IV-G Depressions, irregular or with ill-defined boundaries. IV-H Chäin craters.

*Units not shown in figure 3.

In general, the maria are lower in elevation than the terrae and also have surfaces of lower relief and reflectivity (albedo). Wide troughs and plateaus, bordered by scarps in some places, together with ridges, rilles, domes, and craters lend relief to and disrupt "the topographic continuity of these dark plains. If the linear features and craters were removed, the surface would be almost completely featureless at typical telescopic resolution $(1 \mathrm{~km})$. The most widespread mare type is I-A (table 1). The albedo of the maria is locally, however, very low, and the term "mare, dark" (table 1, I-B) has been used to designate such areas (fig. 3 ); which generally have demonstrably fewer small craters. Relatively smooth plains also occur in the terrae within circular basins or degraded large craters; these plains differ from mare plains by having a higher density of craters that are at and just below the limit of telescopic photography, but visible on Lunar Orbiter photographs. In the Sinus Medii area, depicted in figure 3, most of the mare is of type I-A, with a density of craters and mare ridges that is reasonably representative of other maria areas on the earthside hemisphere.

The terrae in the central part of the equatorial belt are morphologically complex, even at telescopic resolution. Nevertheless, a fourfold division (II-A, II-B, II-C, II-D) evolved after several earlier, unsuccessful classification attempts. Lunar Orbiter photographs show that the terrae are even more complex than had been realized, but the original four divisions are sufficiently general to remain applicable within the map area.

Terra plains of intermediate albedo, II-A, are common at the mare-terra boundaries and also in basins of structural origin or in floors of highly degraded craters (fig. 3). Hummocky to faintly braided terrain, II-B, is widely distributed around the south boundaries of Mare Imbrium and is quite different in texture from the other units. Unit II-C is characterized by subdued linear ridges and troughs (fig. 3) oriented radially to Mare Imbrium. The roughest terrain unit, II-D, consists of strongly lineated terra with isolated positive blocks, steep ridges, and troughs.

Craters, terrain class III, are divided into two main categories: III-A, topographically sharp wellformed craters with or without associated bright rays and III-B, subdued more irregular crater forms, including most of the larger circular features in the terrae. In each of these categories, morphologic subunits can generally be distinguished within larger craters $(>10 \mathrm{~km})$. However, the smaller craters, 2-10 km in diameter, cannot be classified as to type and are, therefore, placed in an undivided unit, III-C (fig. 3). Large relatively unmodified craters, such as Copernicus and Theophilus, exhibit a wide rangê of roughness characteristics at $1 \mathrm{~km}$ resolution, depending on location within a subunit. The interior walls are clearly the least hospitable terrain unit, with slopes of as much as $30^{\circ}$.

Linear features, unit IV, constitute the fourth group of major terrain units. Ridges, rilles (both straight and sinuous), escarpments, chain craters, troughs and elongate plateau areas, and faults and

FIgURE 3.-Terrain of a part of the Sinus Medii area mapped at 1:1,000,000 scale (after Holm and others, 1965). Compare with figure 2 . Table 1 gives descriptions of each unit. Light dashed lines indicate approximate unit boundaries; heavy dashed lines locate narrow linear depressions. Heavy. solid lines indicate faults; solid lines with diamonds and arrows locate ridge crests. Stippled pattern : locates areas of ray deposits. 

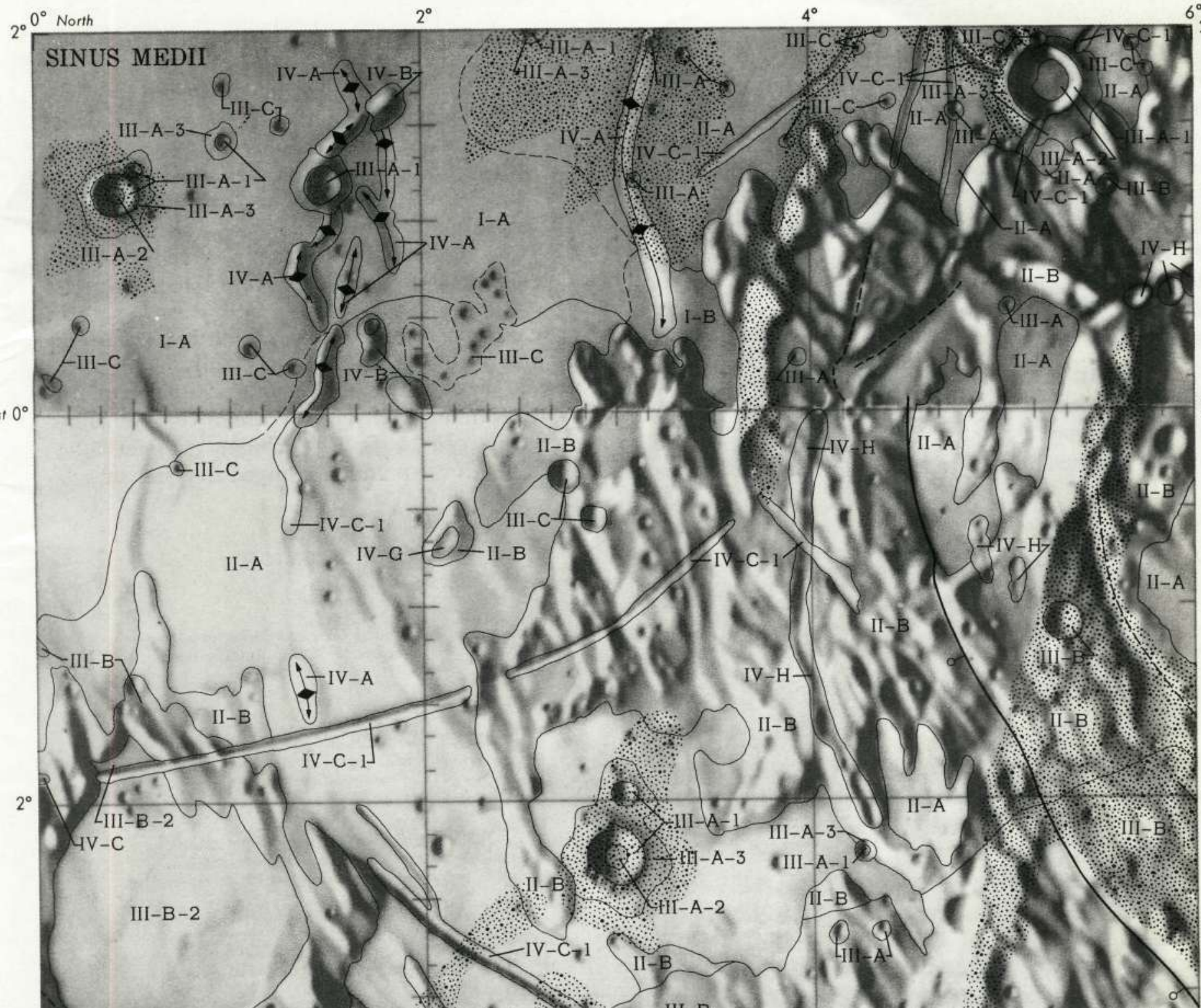

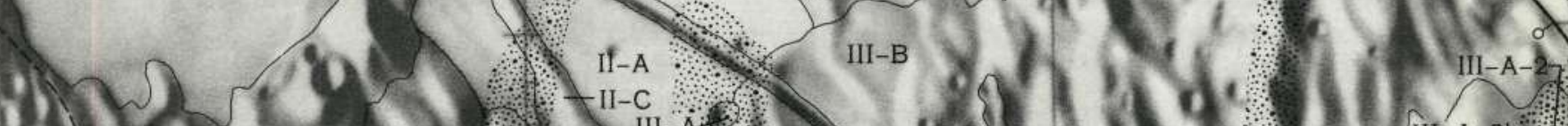

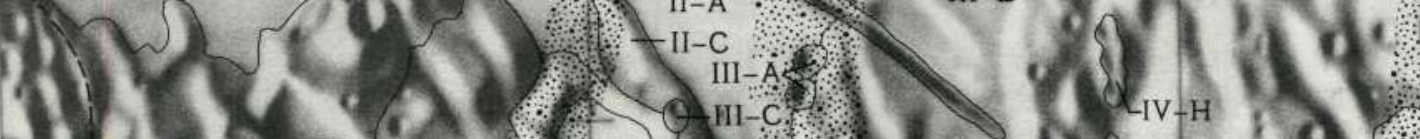

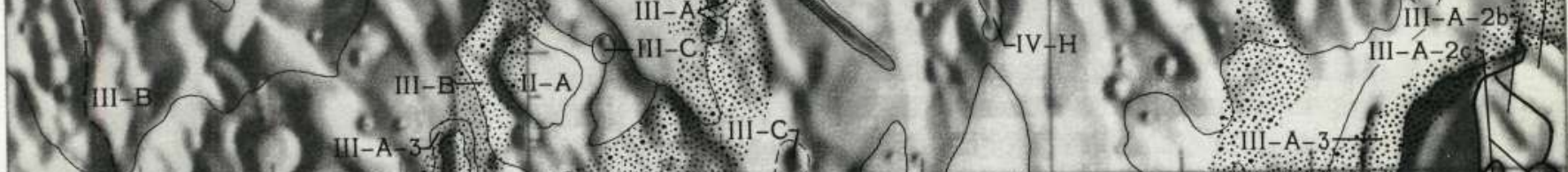

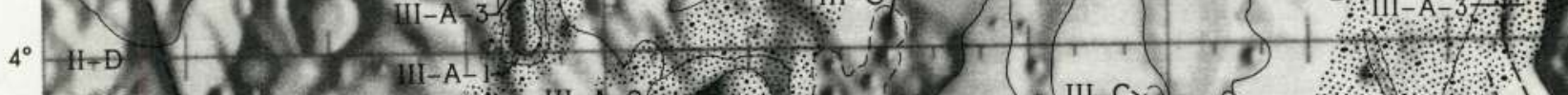

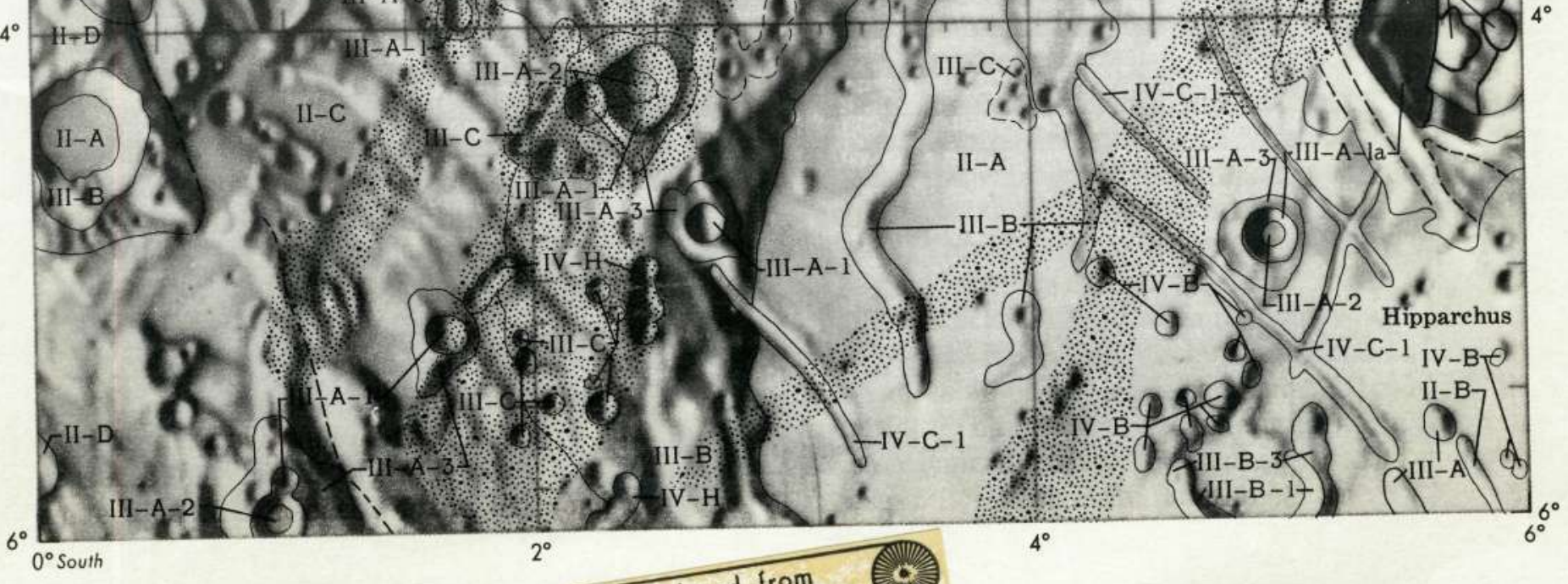

$6^{\circ} 0^{\circ}$ South

Reproduced trom copy.

best available cop 
lineaments each have individual and identifiable topographic expression. The last two are not mappable, however, as units at this scale because of their limited areal extent. (See types of terrain units, figs. 22-29.) The frequency of any one of these types within an area may be such that it dominates the terrain pattern and thus markedly alters the surface roughness. Also included, mostly for convenience, in this category are the round to elliptical domes present locally in the maria.

VISUAL TELESCOPIC TERRAIN MAPPING

Craters as small as a half a kilometer and linear clefts as narrow as 100 meters can be seen with a medium-aperture telescope when viewing at low illu- mination angles. This resolution represents nearly a twofold improvement over the terrain detail on most high-quality lunar telescopic photographs. For this reason a program of visual terrain studies of small selected areas was conducted using primarily the Lick Observatory 36-inch telescope. Ten mare sites were picked on the basis of their apparent smoothness on existing telescopic photographs. Figure 4 shows a map of one of these study areas, north of the crater Flamsteed. It is representative of the visual mapping approach and is of additional interest because it was utilized in the final selection of the Surveyor I landing site. The terrain of the Flamsteed area was divided by. D. F. Crowder (in McCauley, 1964, p. 36) into five units arranged in order of rela-

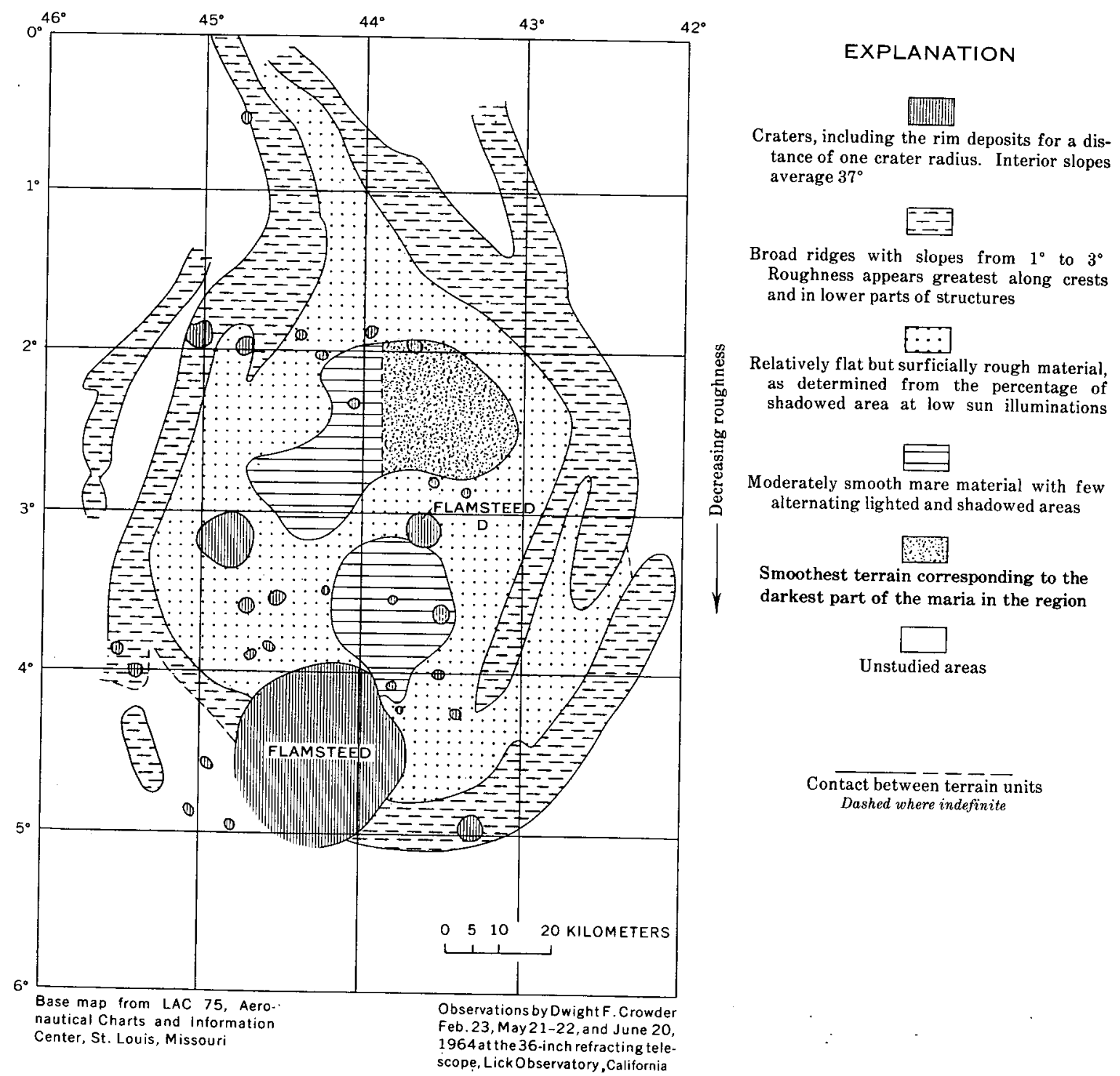

FIGURE 4.-Sample lunar terrain map prepared by visual observation at the Lick 36 -inch refracting telescope. (After McCauley, 1964, fig. 10.) 
tive roughness. Roughness was estimated by the incidence of small resolvable shadows close to the terminator. Regions showing the largest percentage of shadowed terrain alternating with illuminated areas were judged to be the roughest, and those showing the least variation in illumination were considered the smoothest. The smoothest areas are generally coincident with dark mare-a relationship found to be true in the other areas studied visually. Focus on these darker mare areas during the siteselection phase of the Lunar Orbiter program facilitated accomplishment of its primary mission by the third flight and freed the two remaining spacecraft for moon-wide reconnaissance and detailed examination of areas of scientific interest.

One of the major results of the visual terrain studies program was the discovery that ray-covered mare areas are rougher than nonrayed mare areas.

\section{SLOPE-MEASURING PROGRAM}

Strahler $(1950,1954,1956)$ demonstrated that slope is the most important element in quantitative landform classification; Wood and Snell (1959) also showed that slope data are more effective than other topographic quantities for the purpose of terrain classification. Numerous other measures of terrain geometry have been used in terrestrial studies to completely describe the topography, but slope statistics seem most appropriate for relative-roughness studies.

Methods for obtaining reasonably accurate lunar topographic data have existed since the telescopic work of William Herschel and, later, that of Schröter in the 18th century (Kopal, 1962). The total quantity of reliable topographic data at the outset of the terrain studies program was, however, quite meager. The only significant body of useful topographic information consisted of the relative-relief measurements made by the U.S. Air Force Chart and Information Center, St. Louis, Mo., in support of their 1:1,000,000-scale lunar topographic mapping program.

One of the first tasks of this program then was to improve existing slope-measuring techniques so that the major recognizable terrain units could be studied quantitatively. The photometric technique first described by van Diggelen (1951) was selected as the most promising from the standpoint of providing a large quantity of slope data in the shortest possible time. It also has the advantage of being most sensitive in areas of low relief and uniform albedo, the type of terrain most suitable for spacecraft landings. After considerable refinement, the van Diggelen tech- nique was used systematically to generate about 150,000 individual slope measurements, which were later statistically analyzed and used for ordering major terrain units according to their relative roughness (Rowan and McCauley, 1966).

The term "photoclinometry" has been used widely in recent years to describe this method of deriving topographic slope information from lunar imagery (photographic or electronic). The term distinguishes between the techniques of photogrammetry, on the one hand, and the application of lunar photometry to the derivation of topographic data, on the other. As used herein, it is restricted to that aspect of lunar photometry concerned directly with the extraction of slope data from monoscopic pictures. Watson (1968) described the technique in detail, emphasizing its use in extracting slope data from spacecraft images.

\section{PHOTOCLINOMETRY}

The photoclinometric technique depends on a precise knowledge of the lunar photometric function, which is an expression of the reflectance properties of the lunar surface. The geometric conditions for earth-based photoclinometry are considerably less complex than those obtained when viewing the lunar surface from spacecraft, as described by Watson (1968). The description given here will be limited to the simpler case of earth-based observation.

The lunar surface is a strong back-scatterer of incident visible radiation (Minnaert, 1961, p. 222-233), and reflectance is greatest in the direction of the incident beam. The brightness at any point on the lunar surface is a function of the normal albedo and the geometry of the incident and emergent light, so where

$$
B=f(i, e, g) n
$$

$B=$ brightness;

$i=$ the angle of incidence, the angle between the incident ray from the sun and a line perpendicular to the local surface;

$e=$ the angle of emergence, the angle between the emergent ray to the sensor and a line perpendicular to the local surface;

$g=$ the phase angle, the angle between the incident ray and the emergent ray (that is, the sum of $\angle i$ and $\angle e$ ), measured in a plane containing both rays-the phase plane;

$f(i, e, g)=$ the photometric function; and

$n=$ normal albedo.

These relationships are shown in figure 5 .

Lunar photographs taken at oblique angles of illumination show a close correspondence between 


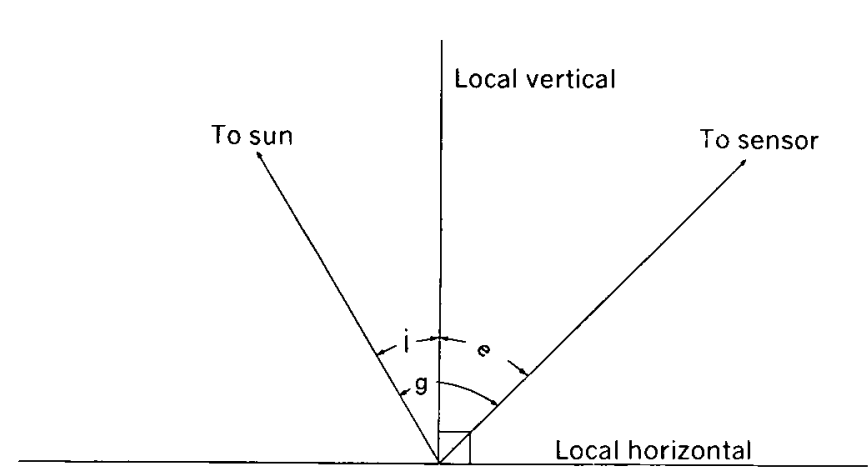

FIGURE 5.-Geometry of the lunar photometric function, where $i=$ angle of incidence; $e=$ angle of emergence; and $g=$ phase angle in the special case where all lie in the same plane.

selenographic longitude (or sun elevation) and isophotes (lines of equal brightness) near the equator (Minnaert, 1961, p. 222-233). This correspondence permits the measurement of slope components in an east-west direction, but provides no slope information in directions not included in the phase plane. Figure 6, a polar view of the moon, illustrates how

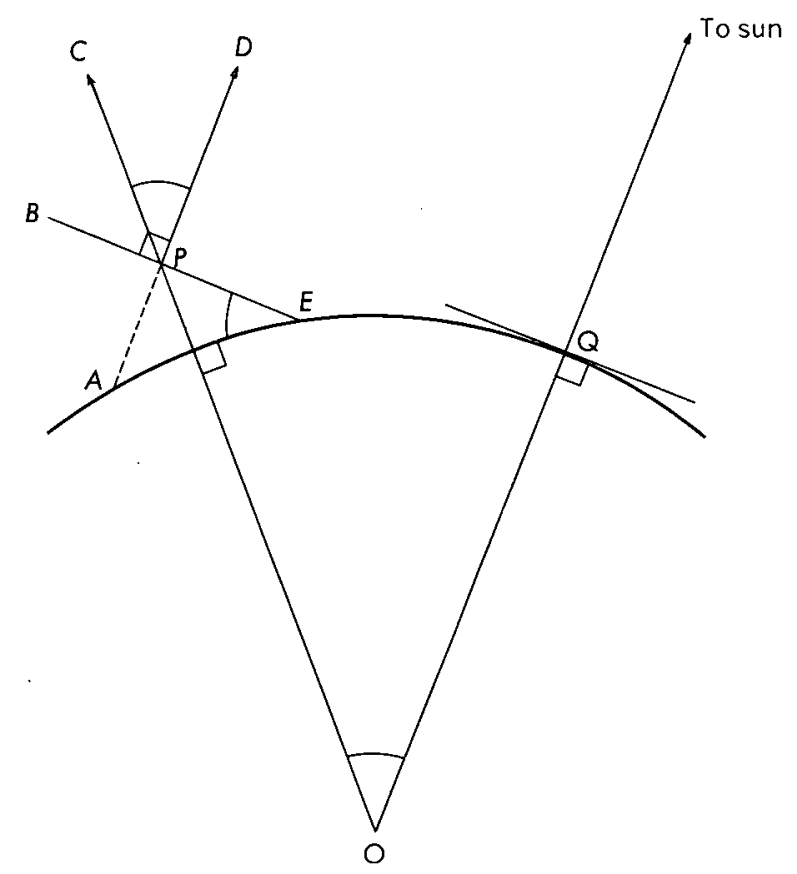

Figure 6.-Polar view of the moon, showing the geometric relations between selenographic longitude and east-west slope components. (After van Diggelen, 1951.)

the slope of a surface element in an area of uniform albedo can be calculated for areas where the illumination conditions are known: Gonsider two topo-

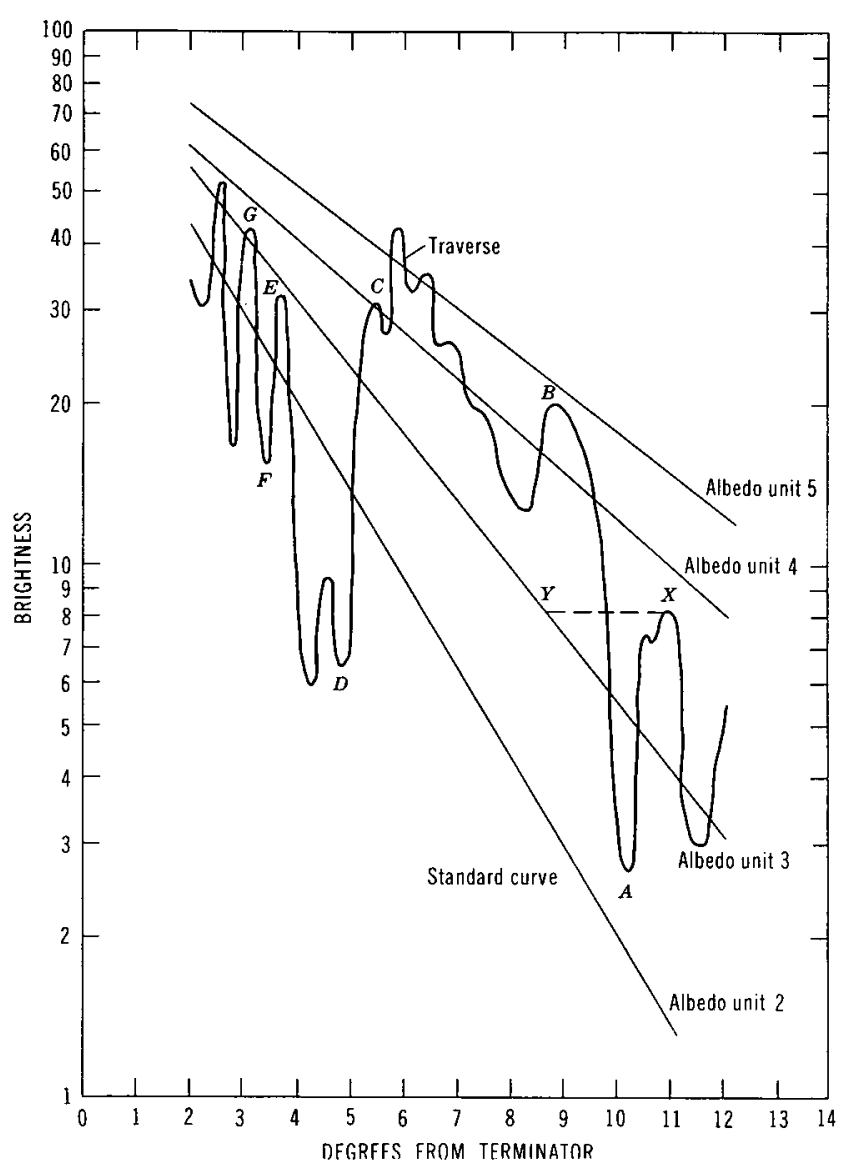

FIGURE 7.-Idealized microphotometer traverse on the lunar surface and the standard curves for different relative albedo units for a particular Iunar photographic plate (negative). The excursions on the traverse are due to both albedo and local slope effects. (After McCauley, 1964, fig. 3.)

graphic elements, $P$ and $Q$, of similar albedo and equal brightness because of their similar angular relations to the sun; element $Q$ is horizontal or tangent to the curvature of the surface, where element $P$ is sloping. The angle of slope of element $P, \angle A E B$ (measured from a tangent to the surface), is given by $\angle C O Q$, the difference in selenographic longitude between the two elements.

$$
\angle A E B=\angle C P D=\angle C O Q
$$

Brightness changes in the east-west direction resulting from changes in the angle of slope can, therefore, be directly equated with changes in sun angle or selenographic longitude, $\angle C O Q$, for topographic elements near the equator. Slope components, in the east-west direction can, therefore, be measured if the photometric function and the effects of albedo variation from element to element can be eliminated. Brightness values that deviate from the average pho- 
tometric function are the result of local slope either toward or away from the sun. The elements sloping toward the sun are brighter for a particular sun elevation angle than elements that are horizontal; conversely, elements sloping away from the sun are darker. The increase in brightness is a measure of the degree of slope determined by comparing the measured value with an empirically derived photometric curve for the particular photograph.

Negative glass copy plates were used on a digitized Jarrel-Ash microphotometer to acquire the lunar slope data. Since the intensity on a negative lunar plate increases exponentially toward the terminator (fig. 7), a semilogarithmic plot of intensity versus sun elevation (or distance from the terminator in selenographic longitude) can be prepared for each plate by systematic sampling of areas determined by inspection to be smooth and of the same albedo. The resulting curve combines the effects of the lunar photometric function and the Herter and Dryfield curve $(H$ and $D)$ of the plate itself. A number of curves, one for each recognizable albedo unit, were derived from the measured intensity values by a least-squares fit; they are referred to herein as standard curves. Departures in intensity from these curves indicate local slope effects in an east-west direction. Figure 7 shows how an individual reading, $X$, within relative albedo unit 3, is compared with a point of equal intensity, $Y$, on the standard curve, to determine the slope of $X$, which is $2.2^{\circ}$. Large-intensity changes such as those between points $A$ and $B$, and $C$ and $D$ (fig. 7) are typically the result of albedo differences, whereas changes such as those between points $E$ and $F$, and $F$ and $G$ generally reflect changes in slope. Individual intensity readings are referred to their appropriate standard curve for slope determination by means of coding introduced during the plate traverse by the microphotometer operator. The intensity readings, referred to the standard curve for the particular albedo unit, are then processed by computer to acquire the actual slope-component data.

Slope determination in areas of varying albedo requires prior categorization of the sample area into relative albedo units. A photographic technique developed by Hawkins and Munsey (1963) and applied by McCauley (1964) to the problem of objectively discriminating relative albedo units was used. The technique consists of successively exposing a fullmoon photograph to a very high contrast copy film (Kodak Ortho-Litho S). The black and clear response of the film to different exposure is utilized to outline isopleths of relative albedo, which then permit the derivation of the previously described standard curve within each albedo unit outlined.

A detailed description of the methodology, the instruments used, the logic of the computer programs employed, and some of the general results of the U.S. Geological Survey slope-measuring program were assembled by D. A. Bremmer (written commun., 1964). This work, along with a description of the first extension of the method to nonmare areas by. Wilhelms (1964) is a useful supplement to the published reference already cited.

\section{LIMITATIONS OF EARTH-BASED PHOTOCLINOMETRY}

Although no systematic error analysis was made, limited comparisons of individual slopes measured photoclinometrically and by use of shadow-length measurements agree to within 10 percent in terrain sloping between $3^{\circ}$ and $10^{\circ}$. In addition, profiles compiled from photoclinometric measurements agree with those prepared from available U.S. Air Force Chart and Information Center LAC charts.

The principal sources of error in earth-based photoclinimetry are (1) nonuniformity of exposure and of development of the photographic plate, (2) variation in resolution within the plate caused by astronomical "seeing effects," (3) errors in determination of local albedo variation which may be falsely interpreted as silope effects, (4) instrumental errors in the microphotometer readings, ${ }^{1}$ (5) errors in selection of the level areas that determine the standard curve for each albedo unit, and (6) selective censoring of the slope data in shadowed areas. The only measurement possible in shadowed areas is that value indicating the slope angle is greater than the sun angle at that point. Thus, the higher slope values along any profile tend to drop out of the slope population as the terminator is approached.

Instrumental errors . can be controlled; however, the relative contributions of each of the other sources of error to individual slope-component measurements cannot be accurately assessed. Clearly the most serious of possible errors stems from the lack of suitable albedo correction. Figure 7 illustrates this problem. If the reading at " $X$ " were referred improperly to albedo unit 2 rather than 3, a 100 percent error in slope measurement would result. Additional unavoidable sampling problems that contribute ambiguity to individual measurements are discussed later in this report.

These limitations are not as serious as they first

\footnotetext{
1 One such problem results from the slightly lesser measuring capability of the microphotometer in areas of high density than in areas of low density on the photographic plate; thus, accuracy of slope-component determination is slightly lower for areas sloping toward the sun than away from it on the
negative plates used.
} 
appear if the main purpose of the measurements is kept in mind. The measurements are not used to produce topographic maps, but serve only as the raw material necessary for statistical evaluation of relative roughness. Erroneous individual slope values are not as important as they would be if topographic mapping were the objective. All the aforementioned types of error can affect slope measurements in each part of the moon sampled, and the overall cumulative error for any block of measurements tends to be uniform. Careful plate selection, determination of albedo variation, microphotometer calibration, and determination of standard curves can keep the total error generally constant so that the relative order of measurable roughness of the units sampled is not changed. Statistically speaking, then, the lunar surface can be described and arranged into progressively rougher units, the relative order of which will not be affected by systematic slope-measuring errors. Owing to these errors, the final measurements may be consistently too high or too low, but the order in which units are ranked will be unaffected. Preliminary comparisons of statistical slope values computed from profiles derived (1) photogrammetrically by S. S. C. Wu and (2) photoclinometrically by Baerbel Lucchitta indicate that the photoclinometric slope measurements are 15-25 percent lower than the photogrammetric ones. The profiles compared were derived. from Apollo 8 photographs and will appear in the published mission report.

\section{RELATIVE RELIEF}

The photoclinometric technique is relatively ineffective for measuring slopes of rough terrain in the terminator region because horizontal surfaces are rare and large areas are in shadow; these factors preclude accurate derivation of the standard curves and causes censoring of the steeper slope values. For these reasons, relative-relief measurements were chosen for statistical analysis of the rougher parts of the equatorial zone.

Relative relief is the vertical displacement of a topographic feature, as measured along a horizontal line. The 1,200 measurements used here were obtained from William Cannell of the U.S. Air Force Chart and Information Center, St. Louis, Mo.; they were made by the shadow technique developed by Kopal (1962). Unlike the slope-component measurements, relative-relief measurements are not confined to $0.75 \mathrm{~km}$ slope lengths, but range from about 3 to $5 \mathrm{~km}$. They are, therefore, not strictly comparable, in terms of resolution, with the values obtained photoclinometrically.

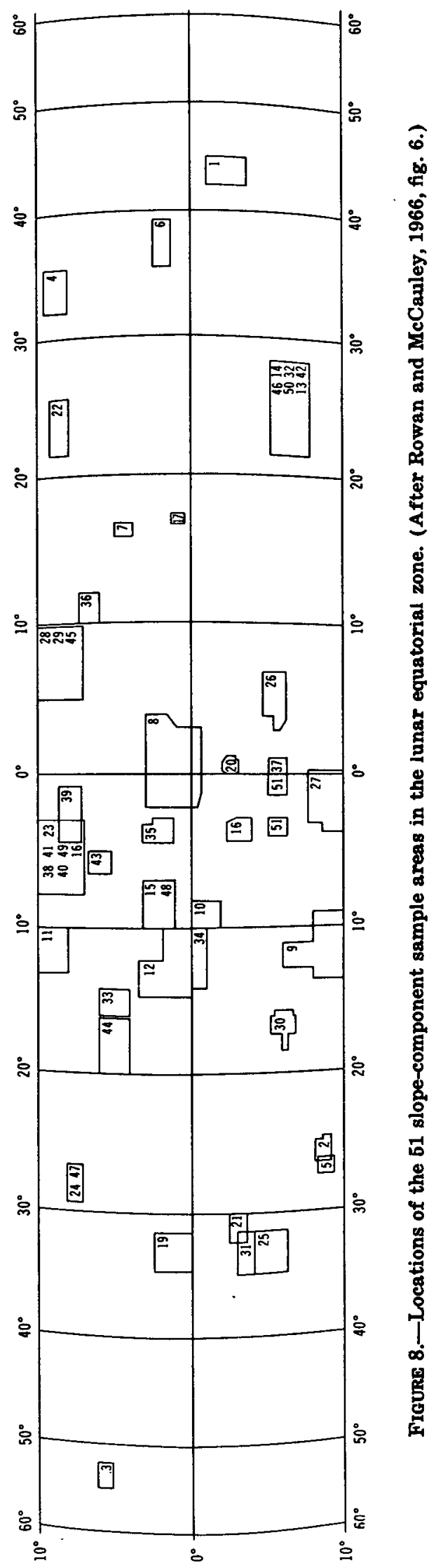




\section{STATISTICAL ANALYSIS}

\section{SAMPLING PROCEDURE}

The engineering applications of ranking terrain according to relative roughness for landing-site selection studies dictate that only standard and easily computed statistical measures be examined. The usefulness of these measures for terrain ranking depends on the accuracy of the measurements themselves and on the degree to which the samples represent the real slope populations at the scale of interest. The estimated accuracy of the measurements has already been discussed, and this section will deal mainly with the sampling procedures, the inherent problems therein, and the effects of these problems on relative-roughness rankings.

Consider two general scale-dependent sample regimes: the terrain map scale, on which the smallest classified features are on the order of tens of kilometers, and the scale of the individual slope-component measurements, each of which is approximately 0.75 $\mathrm{km}$ long. At the 1:1,000,000 map scale, terrain units are delineated visually on the basis of common suites of morphologic characteristics; thus, these units are, at telescopic resolutions, nearly morphologically homogeneous and, therefore, have characteristic slope distributions and relative-relief populations. In most samples, the percentage of area occupied by units other than the populations of primary interest is small, so the slope-component statistics are reasonably representative of the primary population. Some of the 51 slope sample areas (fig. 8) were, however, distinctly heterogeneous and thus had to be divided to obtain morphologic homogeneity.

The most significant sampling problems arise from limitations of the photoclinometric technique and of the measuring equipment used. The photoclinometric technique, as previously shown, is restricted to eastwest measurements, so true slope (maximum slope) measurements are made only when the trend of strike of the sloping surface is north-south; measurements of slopes that do not trend north-south represent a component of the true slope. Unidirectional sampling of this type would have little or no effect if the lunar surface were geometrically random, but many topographic features of the lunar surface are preferentially oriented. Where the trends of these features are known, corrections for the departure from true slope can be made (van Diggelen, 1951), but were not because of the increased computational burden and the judgment that such corrections are not necessary for the type of statistical ranking attempted. Thus, most of the measurements used here are slope components, rather than true slope measurements, and the calculated statistics used for ranking roughness are systematically biased toward lower values. The bias, however, appears to be generally uniform and, therefore, does not seriously detract from the validity of the statistical terrain rankings.

The sample length and the geometry of the terrain also determine the degree to which samples represent real slope populations. The optimum sample length depends on the size of the smallest topographic element of interest. The sample length was limited to approximately $0.75 \mathrm{~km}$ by the resolution of the photographic plates and the aperture of the microphotometer. The effect of this sampling restriction on the slope-component measurements is best considered by examining schematic topographic profiles (fig. 9A) in which the individual slope elements are approximately $0.75 \mathrm{~km}$. A sample less than $0.75 \mathrm{~km}$ long

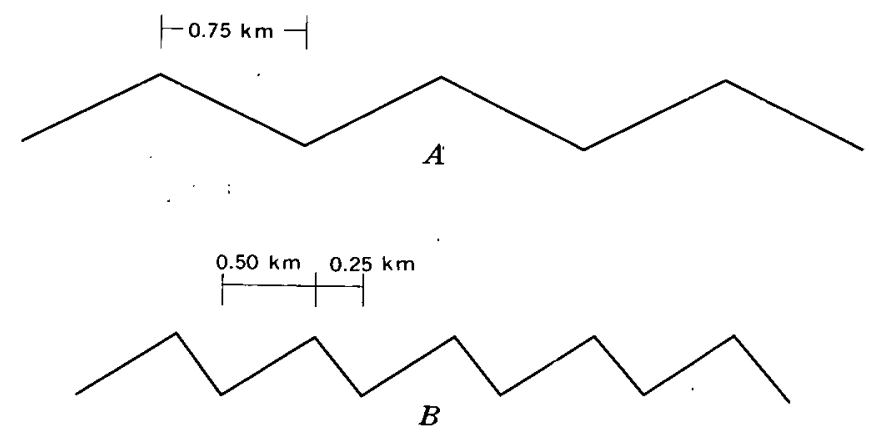

FIGURE 9.-Schematic topographic profiles: $A$, symmetrical topography with individual slope elements $0.75 \mathrm{~km}$ long; $B$, asymmetrical topography with slope elements 0.25 and $0.50 \mathrm{~km}$ long.

yields accurate average slope data, but one larger than $0.75 \mathrm{~km}$ would yield values lower than the actual slopes. A sample length of $1.5 \mathrm{~km}$ gives an average slope value of zero. In practice, alternate $0.75-\mathrm{km}$ samples were recorded because of a limitation of the recording equipment (paper tape punch). This procedure prevents accurate profile construction, but does not affect relative-roughness rankings.

Topographic profile sampling presents problems similar to those inherent in function sampling. In general, the sample interval should be no longer than one-half the wavelength of the sampled function (Nyguist frequency) to avoid producing "aliased" data (Blackman and Tukey, 1958, p. 32). In figure $9 B$, the topographic profile is asymmetric; the sample lengths here must be shorter than the shorter element $(0.25 \mathrm{~km})$ to insure adequate sampling. More complicated arrangements are obviously possible, both with terrestrial and lunar topography.

In general, the number of measurements required 
for adequate representation of a slope-component population depends on the roughness of the area. About 100 slope-component measurements generally suffice for apparently smooth relatively homogeneous areas; $200-300$ are required for rough areas owing to the greater range of dispersion of slopes.

Because of the limited availability and longer slope length $(3-5 \mathrm{~km})$ of the relative-relief data, their usefulness is limited to the rougher terra terrain units (II-B, II-C, II-D). Although these data are useful in describing the relative roughness of the terra, the slope-component data are more widely applicable and will be discussed in more detail.

\section{SLOPE-FREQUENCY DISTRIBUTION FUNCTIONS}

Slope-frequency distribution functions are useful for comparison of slope-component populations because the shape of the distribution curve depends on the frequency of slopes in each class interval. An early application of slope-frequency distributions to lunar terrain classification was made by McCauley $(1964,1965)$, who ranked the six terrain units of the $1: 2,000,000$ scale terrain map by comparing the character of the typical calculated cumulative frequency distribution curve for each unit (fig. 10).

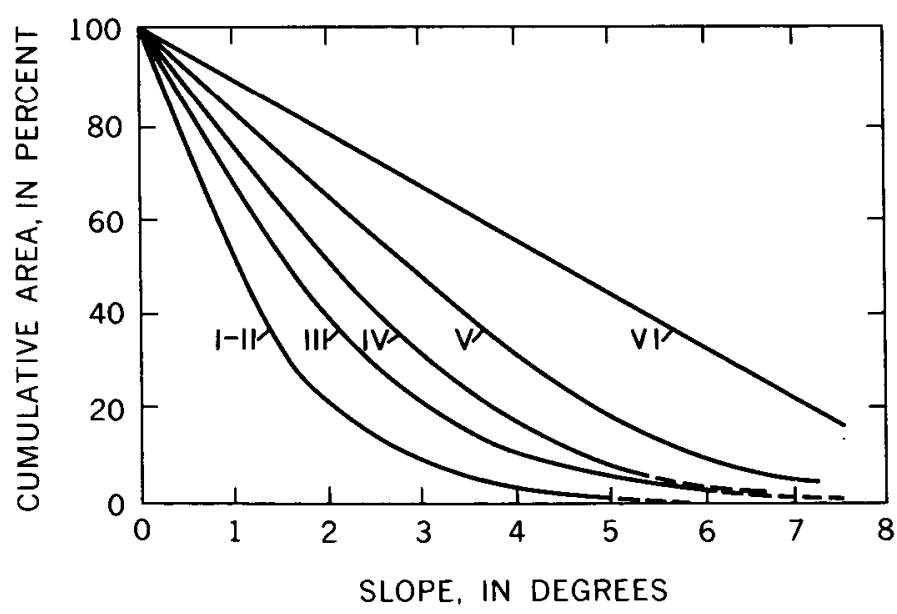

FIGURE 10.-Cumulative slope-component frequency distribution curves for the six terrain units (I through VI) shown on the $1: 2,000,000$-scale terrain map of the lunar equatorial zone. (After McCauley, 1964, fig. 9.)

Statistics, such as the median (50 percentile value) and the 10-90 percentile range, are easily derived from these cumulative frequency curves and are useful for estimating relative-roughness relations. For example, it was shown during early systematic sampling of the equatorial zone that median slope values over $0.75-\mathrm{km}$ slope lengths range from $5^{\circ}$ for the heavily cratered terrae to less than $1^{\circ}$ for typical lunar maria. The $10-90$ percentile range, a measure of the dispersion of the slope values, is also a useful measure of roughness. In general, as the median slope values increase so also does the dispersion. For smooth maria, the dispersion is about $2^{\circ}$, and for the roughest lunar terrain sampled it is about $8^{\circ}$. Also, as the terrain becomes rougher, the area under the slope-frequency curve becomes greater as the curve shifts to the right with increasing median and dispersion values, as shown in figure 10 .

Although slope-frequency data commonly are treated in the absolute sense (Strahler, 1954, p. 12; McCauley, 1964), certain advantages are realized by considering the slope-component direction, as well as the magnitude. In so doing the slope-component populations can be arranged in the form of an algebraic frequency distribution, rather than an absolute frequency distribution.

The advantages gained by treating the slopecomponent data with respect to direction as well as magniture are threefold: (1) the algebraic frequency distributions generally approximate Gaussian, or normal, distributions and are, therefore, described by two statistics, the arithmetic mean and the standard deviation, (2) the frequency of topographic change can be estimated by measuring the number of times that the slope changes algebraic sign in a given population (that is, the percentage of slope reversal ${ }^{2}$ ), and (3) if the algebraic frequency distribution is non-Gaussian, the degree of asymmetry of the terrain can be estimated. The algebraic arithmetic mean and standard deviation, percentage of slope reversal, and the absolute arithmetic mean and median are given in table 2 for each of the areas sampled; the terrain units of each sample area and the location of the area are also listed.

Algebraic slope-frequency distribution curves were derived for all the sample areas by using the $\Phi(z)$ methods (Lindgren and McElrath, 1959, p. 253) for the standard normal distribution function. The fit is good for most of the sample areas. Notable exceptions, however, are samples 20,26 , and 30 (fig. 8; table 2). These deviations appear to result from either inadequate sampling, censoring (as described on p. G11), or superposition of significantly different terrain types. Percentile dispersion values for two typical sample areas $(9,39)$ are shown in figure 11 to illustrate the Gaussian nature of algebraic alopefrequency distributions. For comparison, percentile dispersion values for non-Gaussian, absolute distributions are also shown.

\footnotetext{
2 For example, if in a slope population sample of 100 measurements, the
slope changes sign 10 times, the percentage of slope reversal is 20 .
} 
The value of algebraic slope-component distributions for rapid visual appraisal of relative roughness of widely different lunar terrain types is demonstrated by examining typical mare and terra areas. The maria are characterized by a moderate density of craters in all size ranges and by widely spaced structures, such as ridges, domes, and rilles. Mare Cognitum (sample 9, the area photographed at greater resolution by Ranger VII) is an excellent example of this terrain type. The terrae include a

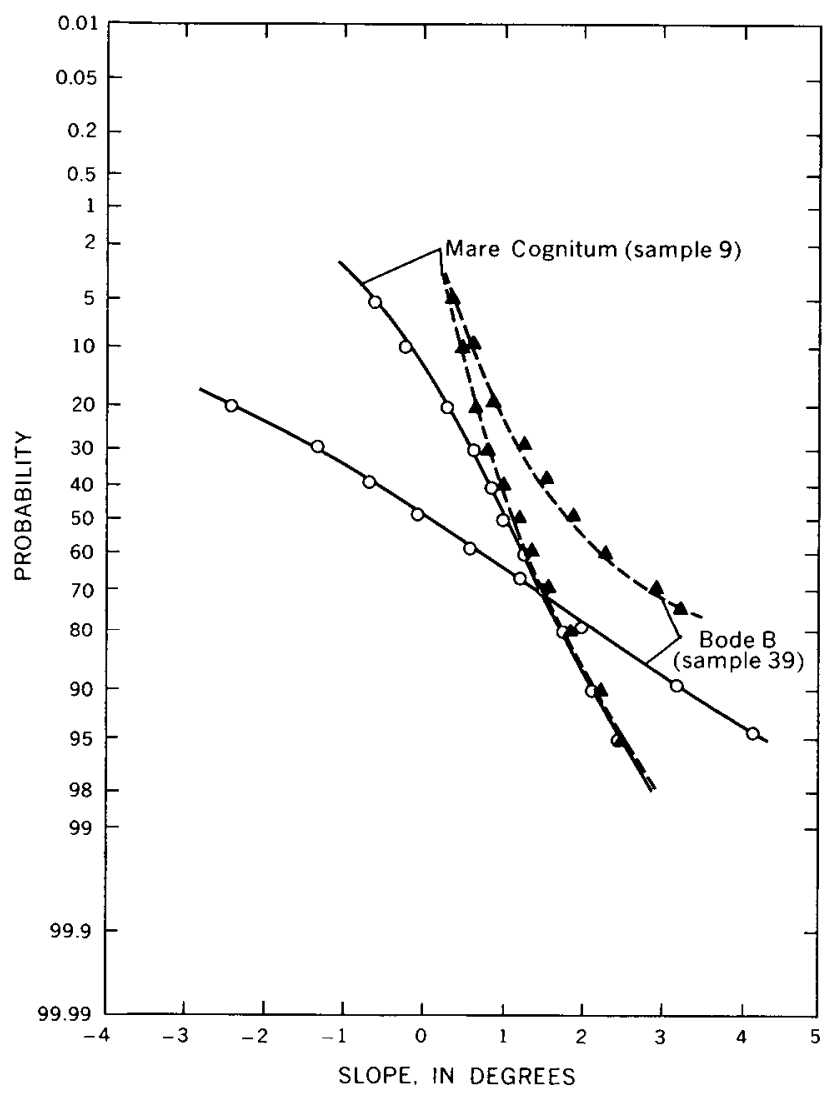

FIGURE 11.-Arithmetic probability plot of slope-component percentile values for typical samples, Mare Cognitum (sample 9) and Bode B (sample 39), showing the Gaussian character of the algebraic frequency distributions (solid line) and the nonGaussian, absolute distributions (dashed line). (After Rowan and McCauley, 1966, fig. 9.)

more complex variety of basic terrain types, from relatively smooth terra plains (generally resembling mare at $0.75 \mathrm{~km}$ resolution) to rougher units composed in great part of a continuum of fresh to erosionally degraded partly buried craters and irregular topographic high unrelated to craters.
In figure 12, three different terrain types are contrasted by comparison of their algebraic slopecomponent frequency distributions. The relatively smooth Mare Cognitum sample (No. 9) is represented by a leptokurtic curve at $0.75-\mathrm{km}$ sample length and has 52 percent of the slope components confined within the $\pm 1^{\circ}$ range. This property is a common characteristic of many of the mare samples (for example, samples 8 and 12). In contrast, the terra (II-D) sample near Herschel (No. 51) exhibits a platykurtic curve. The frequency distribution here shows a greater range of slope-component values because of the greater inherent roughness. In many areas, roughness is intermediate between that of the Mare Cognitum and Herschel samples. Sample 39, for example, exhibits a mesokurtic curve (Bode B, fig. 12). Thus, curves of this general type can be used to evaluate the relative roughness of widely different types of terrain, independent of geologic considerations.

Algebraic slope-frequency distributions for dome. fields (samples 33,47 ) are characteristically bimodal. The degree of separation between the modes depends primarily on the type of dome sampled. The flat subdued Hortensius domes show a small modal separation, whereas the more complex Marius domes (not. included in table 2) show a larger separation.

Many of the mare samples contain several slope populations owing to the presence of features such as rilles and ridges. In the Gambart area (sample 12), hummocky terra remnants, small craters, rays, and low broad ridges are present on the mare (fig. 13 ), and the algebraic frequency curve is mesokurtic (fig. 14A). The degree to which the various populations contribute to the roughness of the mare can be evaluated by excluding these populations individually from the total sample and observing the effects on the resulting slope-component frequency curves $(14 B-F)$. A moderately leptokurtic curve (fig. $14 B$ ) results when the hummocky terra (fig. 13, unit 1) is deleted. Exclusion of the mare ridge (fig. 13, unit 2), the crater fields (fig. 13, unit 3 ), and the ray-covered areas (fig. 13, unit 4), as well as the hummocky terra (fig. 13, unit 1), shows that the character of the curves (fig. $14 C-E$ ) is significantly affected by the superposed ray material, because it is at this point of exclusion (fig. 14E) that the curve becomes markedly leptokurtic. Sampling of the mare area only (fig. 13 , unit 5 ; fig. $14 F$ ), the only sample included in table 2, yields a highly leptokurtic curve.

In contrast to algebraic slope-frequency distributions, which are approximately Gaussian, the absolute slope-frequency distributions are positively 

TABLE 2.-Significant statistical slope-component parameters and the terrain units listed in decreasing order of percentage
area covered for each of the 51 slope-component sample areas (slope lengths $0.75 \mathrm{~km}$ )

$\left[\bar{X}_{\mathrm{A} 1}\right.$, algebraic arithmetic mean; $\sigma_{\mathrm{A} 1}$, algebraic standard deviation; $\bar{X}_{\mathrm{A} b}$, absolute arithmetic mean; $\mathrm{Med}_{\mathrm{Ab}}$, absolute arithmetic mean]

\begin{tabular}{|c|c|c|c|c|c|c|c|c|c|}
\hline Sample area & Sample & $\begin{array}{c}\text { Location } \\
\text { (lat and long) }\end{array}$ & $\begin{array}{c}\text { Number of } \\
\text { measurements }\end{array}$ & $\overline{\boldsymbol{x}}_{\mathrm{Al}}$ & ${ }_{\mathrm{Al}}^{\sigma}$ & $\begin{array}{c}\text { Percentage } \\
\text { slope } \\
\text { reversal }\end{array}$ & $\overline{\boldsymbol{X}}_{\mathrm{Ab}}$ & $\mathrm{Ab}_{\mathrm{Ab}}^{\mathrm{Med}}$ & Map units (table 1) \\
\hline $\begin{array}{l}\text { Mare } \\
\text { Fecunditatis. }\end{array}$ & 1 & $\begin{array}{l}1.2^{\circ}-3.8^{\circ} \mathrm{S} . \\
42.3^{\circ}-44.7^{\circ} \mathrm{E}\end{array}$ & 900 & $-0.14^{\circ}$ & $0.48^{\circ}$ & 26.7 & $0.40^{\circ}$ & $0.32^{\circ}$ & $\begin{array}{l}\text { I-A, IV-A, IV-B, I-B, III-C, } \\
\text { IV-E, rays, III-A. }\end{array}$ \\
\hline $\begin{array}{l}\text { Riphaeus } \\
\text { Mountains. }\end{array}$ & 2 & $\begin{array}{r}8.1^{\circ}-9.2^{\circ} \mathrm{S} . \\
24.7^{\circ}-26.7^{\circ} \mathrm{W}\end{array}$ & 582 & $.38^{\circ}$ & $.38^{\circ}$ & 15.3 & $.34^{\circ}$ & $.29^{\circ}$ & $\begin{array}{l}\text { I-A, IV-A, III-A-3, IV-E, } \\
\text { III-A-1. }\end{array}$ \\
\hline Reiner.......... & 3 & $\begin{array}{l}5.3^{\circ}-6.2^{\circ} \mathrm{N} \\
51.9^{\circ}-54.9^{\circ} \mathrm{W}\end{array}$ & 1,428 & $-.06^{\circ}$ & $.62^{\circ}$ & 15.9 & $.47^{\circ}$ & $.36^{\circ}$ & $\begin{array}{l}\mathrm{I}-\mathrm{A}, \mathrm{IV}-\mathrm{A}, \mathrm{III}-\mathrm{A}-3 \mathrm{a}, \mathrm{III}-\mathrm{A}-3 \mathrm{~b}, \\
\text { and rays. }\end{array}$ \\
\hline Sinas A & 4 & $\begin{array}{l}8.0^{\circ}-9.5^{\circ} \mathrm{N} . \\
32.1^{\circ}-36.5^{\circ} \mathrm{E}\end{array}$ & 551 & $-.20^{\circ}$ & $.78^{\circ}$ & 11.4 & $.68^{\circ}$ & $.64^{\circ}$ & $\begin{array}{l}\text { I-A, IV-A, III-C, III-A-3, } \\
\text { III-A-1, IV-E, and rays. }\end{array}$ \\
\hline $\begin{array}{l}\text { Riphaeus } \\
\text { Mountains. }\end{array}$ & 5 & $\begin{array}{r}8.3^{\circ}-9.3^{\circ} \mathrm{S} . \\
26.2^{\circ}-27.5^{\circ} \mathrm{W} \\
\end{array}$ & 402 & $.56^{\circ}$ & $.85^{\circ}$ & 20.3 & $.72^{\circ}$ & $.43^{\circ}$ & $\begin{array}{l}\text { I-A, IV-A, IV-D, III-A-3, III-A-1, } \\
\text { IV-E, and rays }\end{array}$ \\
\hline Lubbock S . . . . . & 6 & $\begin{array}{l}1.3^{\circ}-2.3^{\circ} \mathrm{N} \\
35.6^{\circ}-39.4^{\circ} \mathrm{E}\end{array}$ & 509 & $.00^{\circ}$ & $.83^{\circ}$ & 16.1 & $.63^{\circ}$ & $.51^{\circ}$ & $\begin{array}{l}\text { I-A, III-C, II-B, II-C, } \\
\text { and IV-G. }\end{array}$ \\
\hline Cayley _....... & 7 & $\begin{array}{l}3.8^{\circ}-4.9^{\circ} \mathrm{N} \\
14.7^{\circ}-16.6^{\circ} \mathrm{E}\end{array}$ & 396 & $-.51^{\circ}$ & $.79^{\circ}$ & 17.9 & $.72^{\circ}$ & $.56^{\circ}$ & $\begin{array}{l}\text { II-A, II-B, III-A-3, III-A-1, } \\
\text { III-A-2, III-C, III-B-1, III-B-2, } \\
\text { III-B, IV-C-1, and rays. }\end{array}$ \\
\hline $\begin{array}{l}\text { Sinus } \\
\text { Medii. }\end{array}$ & 8 & $\begin{array}{l}0.75^{\circ}-3.0^{\circ} \mathrm{N} \\
2.1^{\circ} \mathrm{W}-4.1^{\circ} \mathrm{E}\end{array}$ & 1,451 & $.22^{\circ}$ & $1.13^{\circ}$ & 13.8 & $.87^{\circ}$ & $.69^{\circ}$ & $\begin{array}{l}\text { I-A, IV-A, III-A-3, III-A-1, rays, } \\
\text { II-C, IV-B, II-B, III-A, and } \\
\text { IV-C-1. }\end{array}$ \\
\hline Mare & 9 & $\begin{array}{l}6.0^{\circ}-10.0^{\circ} \mathrm{S} ., \\
8.9^{\circ}-13.2^{\circ} \mathrm{W} .\end{array}$ & 902 & $.23^{\circ}$ & $.99^{\circ}$ & 17.7 & $.79^{\circ}$ & $.65^{\circ}$ & $\begin{array}{l}\text { I-A, II-B, rays, III-A-1, III-A-3, } \\
\text { III-C, IV-A, IV-D, IV-F, IV-E, } \\
\text { III-B-3, III-B-1, and III-A-2. }\end{array}$ \\
\hline Mösting C $\ldots \ldots$ & 10 & $\begin{array}{l}0.0^{\circ}-2.0^{\circ} \mathrm{S} \\
8.15^{\circ}-10.0^{\circ} \mathrm{W}\end{array}$ & 201 & $-.21^{\circ}$ & $1.10^{\circ}$ & 16.4 & $.89^{\circ}$ & $.76^{\circ}$ & I-A, II-A, II-B, rays, and III-A-3. \\
\hline $\begin{array}{l}\text { Sinus } \\
\text { Aestuum. } \\
\end{array}$ & 11 & $\begin{array}{r}8.0^{\circ}-10.0^{\circ} \mathrm{N} \\
10.0^{\circ}-13.0^{\circ} \mathrm{W} \\
\end{array}$ & 440 & $.14^{\circ}$ & $1.34^{\circ}$ & 18.2 & $1.08^{\circ}$ & $.91^{\circ}$ & $\begin{array}{l}\text { I-A, IV-A, rays, III-B-3, IV-C-2, } \\
\text { IV-C-1, IV-H, and III-C }\end{array}$ \\
\hline Gambart......... & 12 & $\begin{array}{l}0.0^{\circ}-3.0^{\circ} \mathrm{N} \\
10.0^{\circ}-14.4^{\circ} \mathrm{W}\end{array}$ & 626 & $.09^{\circ}$ & $1.38^{\circ}$ & 19.0 & $1.11^{\circ}$ & $.91^{\circ}$ & $\begin{array}{l}\text { I-A, IV-A, III-B, rays, II-C, IV-E, } \\
\text { III-A-3, III-A-1, III-A-2, } \\
\text { IV-C-1, and IV-H, }\end{array}$ \\
\hline $\begin{array}{l}\text { Theophilus GA } \\
\text { SA 7-4. }\end{array}$ & 13 & $\begin{array}{r}5.3^{\circ}-8.0^{\circ} \mathrm{S} . \\
21.3^{\circ}-28.4^{\circ} \mathrm{E} \\
\end{array}$ & 360 & $-.24^{\circ}$ & $1.04^{\circ}$ & 36.0 & $.85^{\circ}$ & $.71^{\circ}$ & III-A-3b and I-A. \\
\hline $\begin{array}{l}\text { Theophilus GA } \\
\text { SA 7-3. }\end{array}$ & 14 & $\begin{array}{r}5.3^{\circ}-8.0^{\circ} \mathrm{S} . \\
21.3^{\circ}-28.4^{\circ} \mathrm{E}\end{array}$ & 678 & $-.57^{\circ}$ & $1.41^{\circ}$ & 25.0 & $1.12^{\circ}$ & $.87^{\circ}$ & III-A-3b, II-B, and IV-H. \\
\hline $\begin{array}{l}\text { Schröter G } \\
\text { SA } 6 .\end{array}$ & 15 & $\begin{array}{l}1.0^{\circ}-3.1^{\circ} \mathrm{N} ., \\
7.0^{\circ}-10.1^{\circ} \mathrm{W}\end{array}$ & 493 & $.15^{\circ}$ & $1.10^{\circ}$ & 22.7 & $.83^{\circ}$ & $.62^{\circ}$ & $\begin{array}{l}\text { I-A, IV-A, III-C, rays, IV-E, } \\
\text { III-A-3, III-A-1, III-B-3, } \\
\text { IV-B, and III-A. }\end{array}$ \\
\hline Schröter F...... & 16 & $\begin{array}{l}7.1^{\circ}-10.0^{\circ} \mathrm{N} \\
3.0^{\circ}-8.0^{\circ} \mathrm{W}\end{array}$ & 603 & $.19^{\circ}$ & $1.35^{\circ}$ & 27.2 & $.87^{\circ}$ & $.57^{\circ}$ & $\begin{array}{l}\text { I-A, IV-A,III-C, III-A, IV-B, } \\
\text { II- } B \text {, III- } B-3, \text { III-B-1, II-A, } \\
\text { and rays. }\end{array}$ \\
\hline Dionysius_....... & 17 & $\begin{array}{l}0.3^{\circ}-1.3^{\circ} \mathrm{N} ., \\
16.5^{\circ}-17.3^{\circ} \mathrm{E} .\end{array}$ & 361 & $-.04^{\circ}$ & $.121^{\circ}$ & 33.2 & $.83^{\circ}$ & $.54^{\circ}$ & II-B and II-A. \\
\hline Flammarion...... & 18 & $\begin{array}{l}2.3^{\circ}-4.0^{\circ} \mathrm{S} . \\
2.7^{\circ}-4.2^{\circ} \mathrm{W}\end{array}$ & 226 & $-.27^{\circ}$ & $1.55^{\circ}$ & 22.0 & $1.09^{\circ}$ & $.89^{\circ}$ & $\begin{array}{l}\text { III-B-2a, III-C, III-B, IV-C- } 1 \text {, } \\
\text { III-A, and rays. }\end{array}$ \\
\hline Kunowsky ...... & 19 & $\begin{array}{l}0.0^{\circ}-2.5^{\circ} \mathrm{N} \\
31.6^{\circ}-34.6^{\circ} \mathrm{W}\end{array}$ & 969 & $.07^{\circ}$ & $1.81^{\circ}$ & 14.5 & $1.15^{\circ}$ & $.95^{\circ}$ & $\begin{array}{l}\text { I-A, rays, II-C, III-C, III-A-3, } \\
\text { III-A-I, and III-A-2. }\end{array}$ \\
\hline Réaumur. . . . . & 20 & $\begin{array}{l}1.7^{\circ}-3.3^{\circ} \mathrm{S} . \\
0.1^{\circ} \mathrm{W}-1.1^{\circ} \mathrm{E} .\end{array}$ & 162 & $.03^{\circ}$ & $1.80^{\circ}$ & 19.0 & $1.06^{\circ}$ & $.48^{\circ}$ & III-B-2, III-B, II-A, and IV-C-1. \\
\hline Lansberg D..... & 21 & $\begin{array}{l}2.5^{\circ}-5.6^{\circ} \mathrm{S} . \\
30.0^{\circ}-32.5^{\circ} \mathrm{W}\end{array}$ & 185 & $.15^{\circ}$ & $1.60^{\circ}$ & 17.8 & $1.27^{\circ}$ & $.97^{\circ}$ & $\begin{array}{l}\text { I-A, IV-A, III-A-3, III-A-1, } \\
\text { II-B, IV-B, rays, III-A-2, and } \\
\text { IV-E. }\end{array}$ \\
\hline Arago $E_{\ldots} \ldots \ldots$ & 22 & $\begin{array}{l}9.25^{\circ}-8.0^{\circ} \mathrm{N} ., \\
21.3^{\circ}-25.5^{\circ} \mathrm{E} . \\
\end{array}$ & 822 & $-.17^{\circ}$ & $1.56^{\circ}$ & 23.1 & $1.21^{\circ}$ & $.98^{\circ}$ & $\begin{array}{l}\text { I-A,IV-A, III-C, III-A-1, III-A-3, } \\
\text { IV-B, and rays. }\end{array}$ \\
\hline Schröter F_..... & 23 & $\begin{array}{l}7.1^{\circ}-10.0^{\circ} \mathrm{N} \\
3.0^{\circ}-8.0^{\circ} \mathrm{W}\end{array}$ & 188 & $-.19^{\circ}$ & $1.56^{\circ}$ & 25.0 & $1.17^{\circ}$ & $.84^{\circ}$ & $\begin{array}{l}\text { I-A, IV-C-1, II-B, III-A, III-C, } \\
\text { III-B, and IV-D. }\end{array}$ \\
\hline
\end{tabular}


TABLE 2.-Significant statistical slope-component parameters and the terrain units listed in decreasing order of percentage area covered for each of the 51 slope-component sample areas (slope lengths $0.75 \mathrm{~km}$ )-Continued

\begin{tabular}{|c|c|c|c|c|c|c|c|c|c|}
\hline Sample area & Sample & $\begin{array}{c}\text { Location } \\
\text { (Iat and long) }\end{array}$ & $\begin{array}{c}\text { Number of } \\
\text { measurements }\end{array}$ & $\overline{\mathbf{x}}_{\mathrm{Al}}$ & ${ }_{\mathrm{Al}}$ & $\begin{array}{c}\begin{array}{c}\text { Percentage } \\
\text { slope } \\
\text { reversal }\end{array} \\
\end{array}$ & $\overline{\boldsymbol{x}}_{\mathrm{Ab}}$ & ${ }^{\text {Med }} \mathbf{A b}$ & Map units (table 1) \\
\hline $\begin{array}{l}\text { Hortensius (2) } \\
\text { SA } 1 \text {. }\end{array}$ & 24 & $\begin{array}{l}7.1^{\circ}-8.1^{\circ} \mathrm{N} \\
26.6^{\circ}-29.4^{\circ} \mathrm{W}\end{array}$ & 349 & $.17^{\circ}$ & $2.01^{\circ}$ & 1.52 & $15.2^{\circ}$ & $1.23^{\circ}$ & I-A, rays, and IV-A. \\
\hline Euclides F & 25 & $\begin{array}{l}3.0^{\circ}-6.2^{\circ} \mathrm{S} . \\
31.6^{\circ}-35.0^{\circ} \mathrm{W}\end{array}$ & 1,026 & $.53^{\circ}$ & $1.80^{\circ}$ & 22.6 & $1.44^{\circ}$ & $1.08^{\circ}$ & $\begin{array}{l}\text { I-A,IV-A, rays, III-A-3, III-A-1, } \\
\text { III-C, and IV-E. }\end{array}$ \\
\hline Hipparchus . . . . . & 26 & $\begin{array}{l}4.7^{\circ}-6.2^{\circ} \mathrm{S} \\
3.0^{\circ}-6.9^{\circ} \mathrm{E}\end{array}$ & 404 & $.30^{\circ}$ & $1.38^{\circ}$ & 24.2 & $1.03^{\circ}$ & $.75^{\circ}$ & $\begin{array}{l}\text { III-B-2, III-B, IV-C-1, IV-B, rays, } \\
\text { III-B-1, III-B-3, III-A-3, } \\
\text { III-A-1, III-A-2, and III-A. }\end{array}$ \\
\hline Ptolemaeus ....... & 27 & $\begin{array}{l}7.6^{\circ}-10.0^{\circ} \mathrm{S} . \\
0.5^{\circ} \mathrm{E}-3.6^{\circ} \mathrm{W}\end{array}$ & 805 & $-.06^{\circ}$ & $1.69^{\circ}$ & 27.0 & $1.14^{\circ}$ & $.83^{\circ}$ & $\begin{array}{l}\text { III-B-2a, III-B, III-B-2, III-B-1, } \\
\text { III-B-3, III-A-3, III-A-1, } \\
\text { III-A-2, and IV-H. }\end{array}$ \\
\hline $\begin{array}{l}\text { Hyginus Rille } \\
\text { SA } 1 . \\
\end{array}$ & 28 & $\begin{array}{l}7.0^{\circ}-10.0^{\circ} \mathrm{N} \\
4.9^{\circ}-9.9^{\circ} \mathrm{E}\end{array}$ & 1,042 & $.10^{\circ}$ & $1.93^{\circ}$ & 21.8 & $1.41^{\circ}$ & $1.10^{\circ}$ & $\begin{array}{l}\text { II-A, III-C, III-A, IV-C-1, } \\
\text { III-A-3, II-C, and III-A-1. }\end{array}$ \\
\hline $\begin{array}{l}\text { Hyginus Rille } \\
\text { SA 2. } \\
\end{array}$ & 29 & $\begin{array}{l}7.0^{\circ}-10.0^{\circ} \mathrm{N} \\
4.9^{\circ}-9.9^{\circ} \mathrm{E}\end{array}$ & 248 & $-.25^{\circ}$ & $1.93^{\circ}$ & 27.4 & $1.49^{\circ}$ & $1.22^{\circ}$ & $\begin{array}{l}\text { II-B, IV-C-1, III-A-3, III-A-1, } \\
\text { and III-A. }\end{array}$ \\
\hline Fra Mauro..... & 30 & $\begin{array}{l}5.2^{\circ}-6.9^{\circ} \mathrm{S},{ }^{\circ} \\
15.5^{\circ}-18.0^{\circ} \mathrm{W}\end{array}$ & 282 & $.09^{\circ}$ & $1.84^{\circ}$ & 21.2 & $1.51^{\circ}$ & $1.35^{\circ}$ & $\begin{array}{l}\text { II-B, II-D, III-B-2a, IV-C-1, } \\
\text { III-A-3, III-A-1, rays, III-B-1, } \\
\text { III-C, and III-B-3. }\end{array}$ \\
\hline Lansberg DB...- & 31 & $\begin{array}{l}3.1^{\circ}-4.1^{\circ} \mathrm{S} . \\
35.0^{\circ}-31.6^{\circ} \mathrm{W}\end{array}$ & 569 & $-.23^{\circ}$ & $1.98^{\circ}$ & 25.1 & $1.49^{\circ}$ & $1.16^{\circ}$ & $\begin{array}{l}\text { I-A, IV-A, III-A-3, III-A-1, rays, } \\
\text { and III-C. }\end{array}$ \\
\hline $\begin{array}{l}\text { Theophilus GA } \\
\text { SA 6. }\end{array}$ & 32 & $\begin{array}{r}5.3^{\circ}-8.0^{\circ} \mathrm{S} . \\
21.3^{\circ}-28.4^{\circ} \mathrm{E} . \\
\end{array}$ & 560 & $.00^{\circ}$ & $1.64^{\circ}$ & 27.1 & $1.14^{\circ}$ & $.78^{\circ}$ & I-A, IV-H, IV-F, and III-A. \\
\hline Fauth G........ & 33 & $\begin{array}{l}4.0^{\circ}-6.0^{\circ} \mathrm{N} \\
14.0^{\circ}-16.0^{\circ} \mathrm{W}\end{array}$ & 148 & $.12^{\circ}$ & $1.79^{\circ}$ & 27.7 & $1.41^{\circ}$ & $1.17^{\circ}$ & $\begin{array}{l}\text { II-C, I-B, IV-B, IV-C-1, rays, } \\
\text { I-A, III-C, and III-A-3b. }\end{array}$ \\
\hline Turner.......... & 34 & $\begin{array}{l}0.0^{\circ}-1.0^{\circ} \mathrm{S} \\
10.0^{\circ}-14.0^{\circ} \mathrm{W}\end{array}$ & 272 & $-.21^{\circ}$ & $1.46^{\circ}$ & 21.0 & $1.18^{\circ}$ & $.98^{\circ}$ & $\begin{array}{l}\text { I-A, rays, IV-A, II-B, II-C, } \\
\text { IV-D, IV-E, III-A-1, III-A-3, } \\
\text { III-C, and III-A. }\end{array}$ \\
\hline Pallas D....... & 35 & $\begin{array}{l}1.5^{\circ}-3.2^{\circ} \mathrm{N} \\
2.6^{\circ}-4.5^{\circ} \mathrm{W}\end{array}$ & 224 & $.30^{\circ}$ & $2.14^{\circ}$ & 22.7 & $1.62^{\circ}$ & $1.40^{\circ}$ & $\begin{array}{l}\text { I-A, II-A, IV-A, IV-D, II-C, } \\
\text { II-C, IV-E, III-C, III-A-3, } \\
\text { III-A-1, III-B-3, III-B-1, III-A, } \\
\text { and III-A-2. }\end{array}$ \\
\hline Silberschlag P. . - & 36 & $\begin{array}{r}6.0^{\circ}-7.5^{\circ} \mathrm{N} . \\
10.0^{\circ}-12.0^{\circ} \mathrm{E} \\
\end{array}$ & 145 & $-.11^{\circ}$ & $2.50^{\circ}$ & 26.2 & $1.94^{\circ}$ & $1.46^{\circ}$ & $\begin{array}{l}\text { II-B, III-C, III-A, III-A-3, } \\
\text { III-A-1, and rays. }\end{array}$ \\
\hline Glyden $\ldots . . . . .$. & 37 & $\begin{array}{l}5.0^{\circ}-6.0^{\circ} \mathrm{S} . \\
0.0^{\circ}-1.2^{\circ} \mathrm{E} \text {. }\end{array}$ & 79 & $.24^{\circ}$ & $2.53^{\circ}$ & 29.0 & $1.89^{\circ}$ & $1.43^{\circ}$ & $\begin{array}{l}\text { II-C, IV-A-3, II-D, III-A-2, } \\
\text { III-A-1, and rays. }\end{array}$ \\
\hline Schroter F...... & 38 & $\begin{array}{l}7.1^{\circ}-10.0^{\circ} \mathrm{N} \\
3.0^{\circ}-8.0^{\circ} \mathrm{W}\end{array}$ & 590 & $-.57^{\circ}$ & $2.31^{\circ}$ & 30.8 & $1.83^{\circ}$ & $1.51^{\circ}$ & $\begin{array}{l}\text { II-B,III-A-3, III-A-1, III-A-2. } \\
\text { IV-C-1, III-B, IV-H, III-B-3, } \\
\text { III-B-1. IV-G, III-C, and III-A. }\end{array}$ \\
\hline Bode B & 39 & $\begin{array}{l}7.0^{\circ}-9.0^{\circ} \mathrm{N} \\
1.0^{\circ}-4.5^{\circ} \mathrm{W}\end{array}$ & 449 & $.06^{\circ}$ & $2.81^{\circ}$ & 23.8 & $2.20^{\circ}$ & $1.82^{\circ}$ & $\begin{array}{l}\text { II-B, I-A, III-A-3, III-A-1, } \\
\text { III-A-2, II-A, III-C, III-B-3, } \\
\text { III-B-1, rays, III-A, III-B, } \\
\text { IV-C-2, and IV-C-1. }\end{array}$ \\
\hline Schroter F $\ldots \ldots$ & 40 & $\begin{array}{l}7.1^{\circ}-10.0^{\circ} \mathrm{N} \\
3.0^{\circ}-8.0^{\circ} \mathrm{W}\end{array}$ & 430 & $-.23^{\circ}$ & $2.42^{\circ}$ & 34.9 & $1.84^{\circ}$ & $1.46^{\circ}$ & $\begin{array}{l}\text { II-B, III-B, III-A-3, III-A-1, } \\
\text { III-C, IV-G, III-B-3, III-B-1, } \\
\text { and IV-C-2. }\end{array}$ \\
\hline Schroter $\mathbf{F}_{\ldots} \ldots$ & 41 & $\begin{array}{l}7.1^{\circ}-10.0^{\circ} \mathrm{N} \\
3.0^{\circ}-8.0^{\circ} \mathrm{W}\end{array}$ & 218 & $-.44^{\circ}$ & $2.63^{\circ}$ & 32.1 & $2.03^{\circ}$ & $1.66^{\circ}$ & II-B and II-C. \\
\hline $\begin{array}{l}\text { Theophilus GA } \\
\text { SA 7-2. }\end{array}$ & 42 & $\begin{array}{r}5.3^{\circ}-8.0^{\circ} \mathrm{S} . \\
21.3^{\circ}-28.4^{\circ} \mathrm{E}\end{array}$ & 77 & $.06^{\circ}$ & $2.53^{\circ}$ & 35.0 & $1.98^{\circ}$ & $1.53^{\circ}$ & II-B, III-A-3b, and III-C. \\
\hline Schroter A9..... & 43 & $\begin{array}{l}5.1^{\circ}-6.6^{\circ} \mathrm{N} . \\
7.9^{\circ}-9.5^{\circ} \mathrm{W} \\
\end{array}$ & 594 & $-.46^{\circ}$ & $2.80^{\circ}$ & 32.2 & $1.92^{\circ}$ & $1.37^{\circ}$ & $\begin{array}{l}\text { II-B, I-A, IV-A, III-C, III-B-3, } \\
\text { and III-B-1. }\end{array}$ \\
\hline Fauth $\ldots \ldots$ & 44 & $\begin{array}{r}4.0^{\circ}-6.0^{\circ} \mathrm{N} \\
16.0^{\circ}-20.0^{\circ} \mathrm{W} \\
\end{array}$ & 4,096 & $20 .^{\circ}$ & $2.96^{\circ}$ & 24.4 & $2.20^{\circ}$ & $1.76^{\circ}$ & $\begin{array}{l}\text { II-C, I-B, III-A-3b, IV-G, III-A, } \\
\text { IV-H, and IV-C-1. }\end{array}$ \\
\hline $\begin{array}{l}\text { Hyginus Rille } \\
\text { SA } 3 .\end{array}$ & 45 & $\begin{array}{l}7.0^{\circ}-10.0^{\circ} \mathrm{N} . \\
4.9^{\circ}-9.9^{\circ} \mathrm{E}\end{array}$ & 864 & $.35^{\circ}$ & $2.87^{\circ}$ & 23.5 & $2.29^{\circ}$ & $1.98^{\circ}$ & $\begin{array}{l}\text { II-B, II-C, III-A, III-C, III-A-3, } \\
\text { III-A-1, IV-H, and IV-G. }\end{array}$ \\
\hline
\end{tabular}


TABLE 2.-Significant statistical slope-component parameters and the terrain units listed in decreasing order of percentage area covered for each of the 51 slope-component sample areas (slope lengths $0.75 \mathrm{~km}$ ) -Continued

\begin{tabular}{|c|c|c|c|c|c|c|c|c|c|}
\hline Sample area & Sample & $\begin{array}{c}\text { Location } \\
\text { (lat and long) }\end{array}$ & $\begin{array}{c}\text { Number of } \\
\text { measurements }\end{array}$ & $\bar{x}_{\mathrm{A} 1}$ & ${ }^{o} \mathrm{Al}$ & $\begin{array}{c}\text { Percentage } \\
\text { slope } \\
\text { reversal }\end{array}$ & $\overline{\boldsymbol{x}}_{\mathrm{Ab}}$ & ${ }_{\mathrm{Ab}}^{\mathrm{Med}}$ & Map units (table 1) \\
\hline $\begin{array}{l}\text { Theophilus GA } \\
\text { SA 1. }\end{array}$ & 46 & $\begin{array}{r}5.3^{\circ}-8.0^{\circ} \mathrm{S} ., \\
21.3^{\circ}-28.4^{\circ} \mathrm{E}\end{array}$ & 225 & $-.35^{\circ}$ & $2.83^{\circ}$ & 32.9 & $2.12^{\circ}$ & $1.63^{\circ}$ & III-A-3b and IV-C-1. \\
\hline $\begin{array}{l}\text { Hortensius (2) } \\
\text { SA } 2 \text {. }\end{array}$ & 47 & $\begin{array}{l}7.1^{\circ}-8.1^{\circ} \mathrm{N} . \\
26.6^{\circ}-29.4^{\circ} \mathrm{W}\end{array}$ & 77 & $-.04^{\circ}$ & $3.68^{\circ}$ & 29.9 & $2.92^{\circ}$ & $2.53^{\circ}$ & IV-B, II-C, IV-H, IV-A, and rays. \\
\hline $\begin{array}{l}\text { Schröter G...... } \\
\text { SA 3. }\end{array}$ & 48 & $\begin{array}{l}1.0^{\circ}-3.1^{\circ} \mathrm{N} \\
3.0^{\circ}-8.0^{\circ} \mathrm{W}\end{array}$ & 401 & $-.58^{\circ}$ & $3.74^{\circ}$ & 29.4 & $2.20^{\circ}$ & $1.35^{\circ}$ & $\begin{array}{l}\text { II-B, III-C, IV-C-1, III-B-3, } \\
\text { III-B-1, and rays. }\end{array}$ \\
\hline Schroter F . ..... & 49 & $\begin{array}{l}7.1^{\circ}-10.0^{\circ} \mathrm{N} \\
3.0^{\circ}-8.0^{\circ} \mathrm{W}\end{array}$ & 270 & $.51^{\circ}$ & $3.63^{\circ}$ & $38.1^{\circ}$ & $2.87^{\circ}$ & $2.32^{\circ}$ & $\begin{array}{l}\text { II-C, II-B, I-A, III-A-3, and } \\
\text { III-A-1. }\end{array}$ \\
\hline Theopilus GA _. & 50 & $\begin{array}{l}5.3^{\circ}-8.0^{\circ} \mathrm{S} . \\
21.3^{\circ}-28.4^{\circ} \mathrm{E} .\end{array}$ & 382 & $-.12^{\circ}$ & $4.29^{\circ}$ & 22.0 & $3.54^{\circ}$ & $3.23^{\circ}$ & II-D, III-B-3, IV-H, and III-B-1. \\
\hline Herschel........ & 51 & $\begin{array}{l}5.0^{\circ}-6.6^{\circ} \mathrm{S} ., \\
4.0^{\circ}-2.7^{\circ} \mathrm{W} . \\
\text { and } \\
1.3^{\circ} \mathrm{W}-1.2^{\circ} \mathrm{E} .\end{array}$ & 290 & $-.08^{\circ}$ & $4.06^{\circ}$ & 29.4 & $3.21^{\circ}$ & $2.69^{\circ}$ & $\begin{array}{l}\text { III-A-3, II-D, II-C, III-B, } \\
\text { III-A-3, III-A-1, III-A-2, and } \\
\text { IIII-C. }\end{array}$ \\
\hline
\end{tabular}

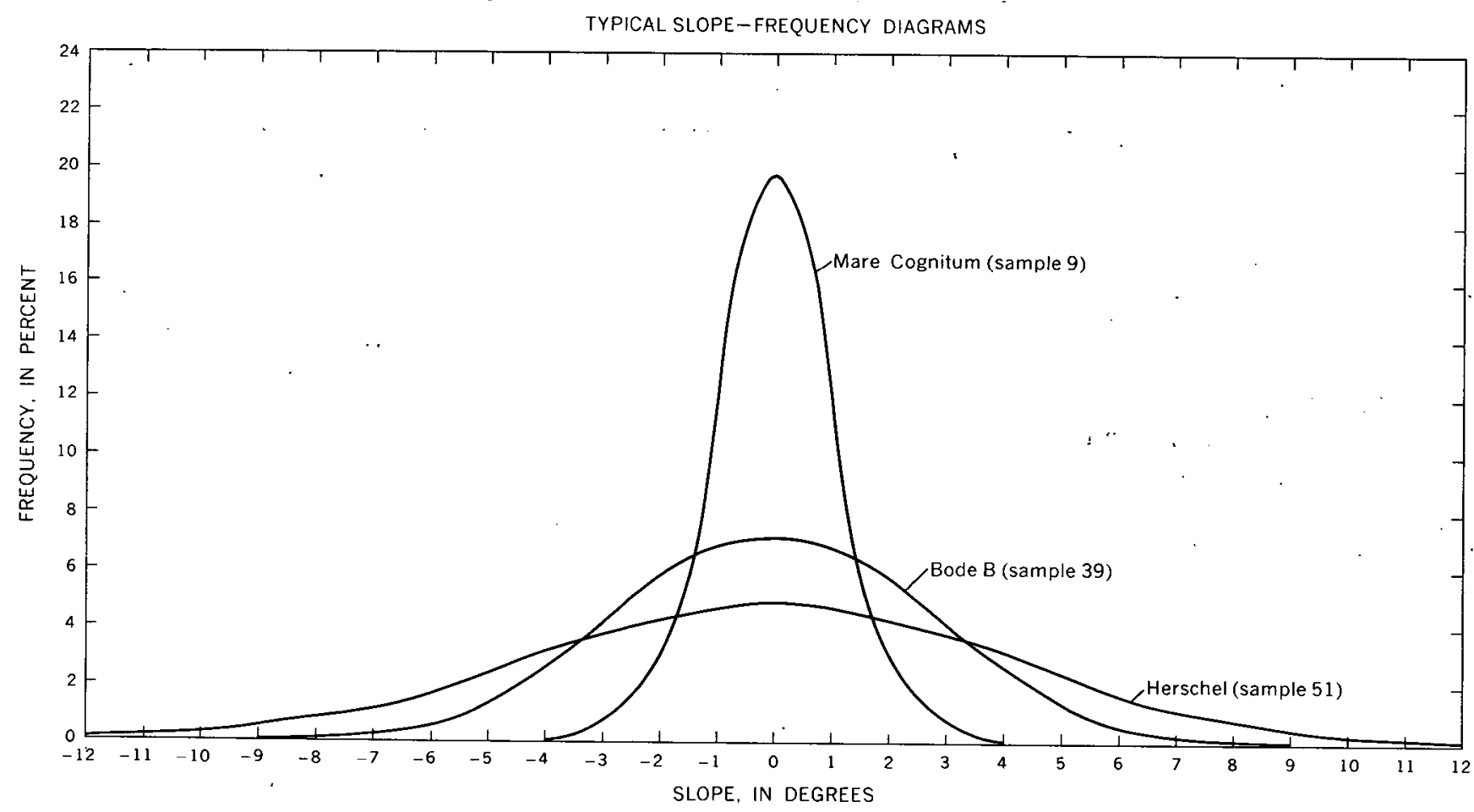

Figure 12.-Algebraic slope-component frequency distribution curves for three typical lunar terrain samples, showing the effects of terrain roughness. (After Rowan and McCauley, 1966, fig. 10.) 


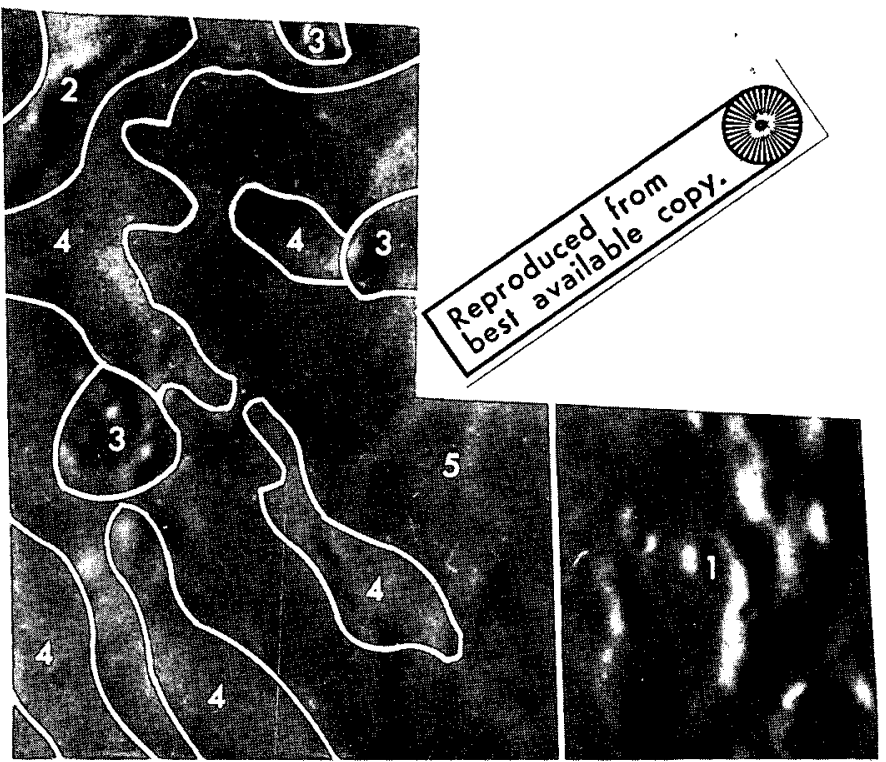

FIgURE 13.-Telescopic photograph (Pease No. 192, Mount Wilson Observatory) of the Gambart area (sample 12), with the nature and extent of different slope-component populations outlined. 1 , hummocky terra; 2, mare ridge; 3 , crater field; 4, ray-covered area; 5, mare. (After Rowan and McCauley, 1966, fig. 11.)

skewed and are, therefore, non-Gaussian. Curves fitted to the absolute frequency distributions are "reversed J-shaped curves," characteristic of folded normal frequency distributions (Leone and others, 1961). Accurate estimates of central tendency and dispersion values from non-Gaussian frequency distributions require transformation to the standard normal distribution. To avoid this laborious task, which could be facilitated by computer processing, algebraic rather than absolute slope-frequency distribution curves were used as the principal terrain rating values in this study.

\section{SLOPE-COMPONENT STATISTICS}

In describing frequency distribution functions, two general types of statistics are commonly used: central tendency and dispersion values. Both the arithmetic mean, $\bar{X}$, and the median are central tendency measures, whereas the standard deviation, $\sigma$, is the most widely used expression to indicate dispersion of population distributions. Somewhat less commonly used values are the mode, the class interval with the highest frequency, and the $10-90$ percentile dispersion. Of occasional value are the skewness, which is an expression of the departure from the normal frequency distribution, and the kurtosis, which measures peakedness of the distribution.

To assess the value of each of these statistics as measures of relative roughness, all were calculated and evaluated for each of the 51 slope-component sample areas. Listed in table 2 are those statistics that appear most useful; the subscripts, Ab and Al, indicate values taken from absolute and arithmetic slope-component frequency distributions, respectively.

Evaluation of all the standard statistical values of the slope-component samples suggests that those most useful as relative-roughness parameters are the absolute arithmetic mean, $\bar{X}_{\mathrm{Ab}}$, the algebraic standard deviation, $\sigma_{\mathrm{Al}}$, and the percentage of slope reversal; of somewhat more limited use is the algebraic arithmetic mean, $\bar{X}_{\mathrm{Al}}$. The meaning of these statistics in terms of relative roughness is demonstrated by the schematic topographic profiles in figure $\mathbf{1 5}$, which show progressively decreasing wavelengths, $W$, and increasing amplitudes, $A$, and, consequently, progressively rougher terrain. To completely describe these profiles, only representative values of $W$ and $A$ are necessary. If the sampling procedure could be controlled so that the sample length was always $W / 2$ and in phase, $W$ and $A$ would effectively describe the surface. Controlled sampling of this type was, of course, not possible in this study, and moreover, terrain profiles are rarely simple single functions. Thus, the slope-component samples are only statistical representatives of the real roughness of the terrain units previously described on the 1:1,000,000-scale map.

In the schematic profiles, the topographic texture or frequency could be estimated by the percentage of changes of direction of the slope from positive to negative (that is, the percentage of slope reversal). The percentage of slope reversal would, at a constant sampling cell length and rate, be greater in the highfrequency (rough) terrain (fig. $15 \mathrm{C}$ ) than in the lowfrequency (smooth) areas (fig. 15A, $B$ ). Slope reversal values are particularly useful because they provide a means of distinguishing between slopecomponent populations which have similar arithmetic means and standard deviations but different topographic textures.

Slope and relative-relief measurements obtained at the same sample length are, of course, simply related and can be of equal value in expressing relative roughness, but slope-component statistics were the principal ranking tool because of the ease by which they are generated from photoclinometry. As previously mentioned, the arithmetic mean, $\bar{X}$, is a measure of the central tendency and is, therefore, the average value of the slope-component frequency distribution. The absolute arithmetic mean, $\bar{X}_{\mathrm{Ab}}$, of the schematic profiles (fig. 15) increases as the slopes increase, but the algebraic arithmetic mean, $\bar{X}_{\mathrm{Al}}$, will 

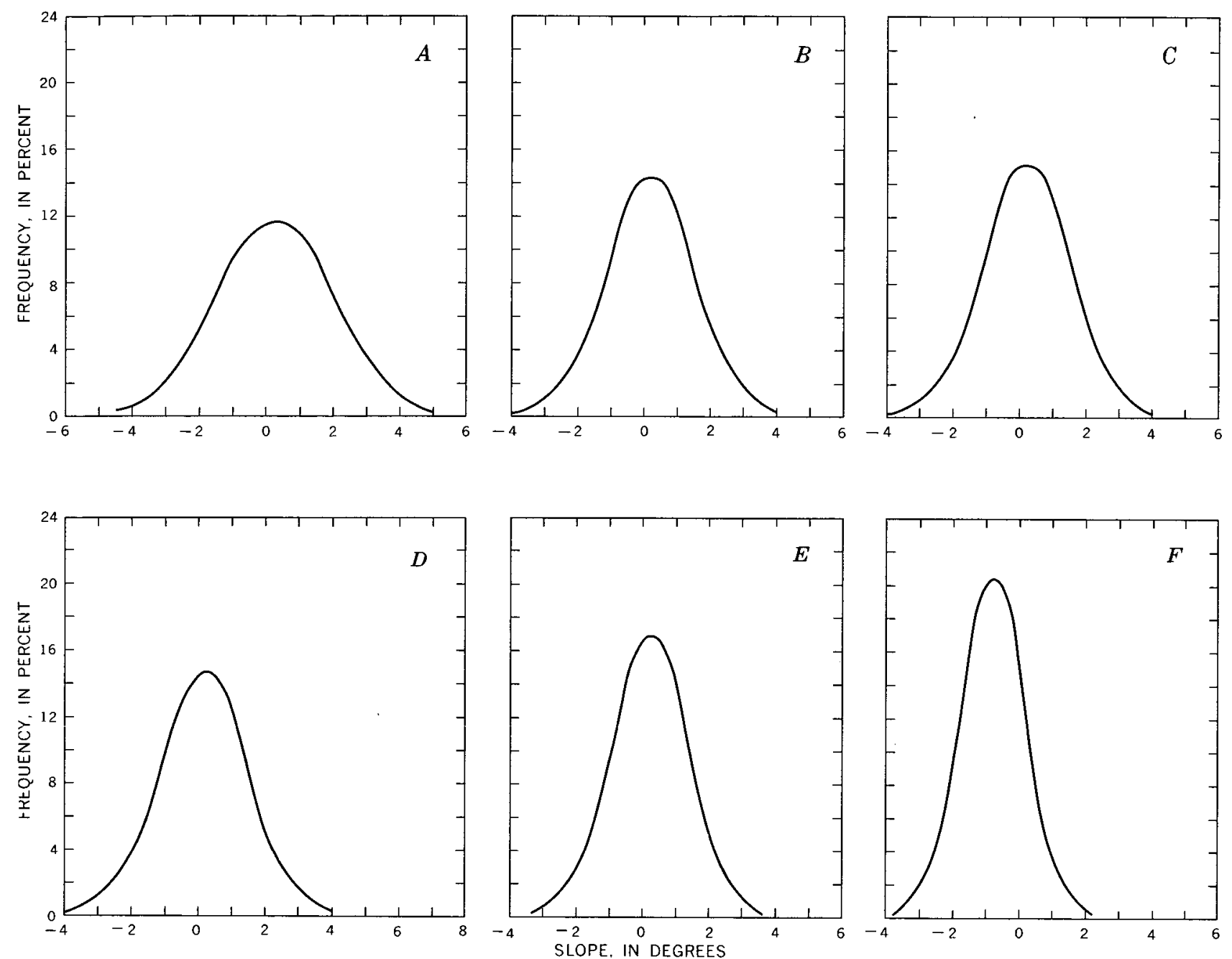

FIGURE 14.-Algebraic slope-component frequency distribution curves for the Gambart sample area (No. 12) with various slope-component populations shown in figure 13 deleted: $(A)$ total sample area; $(B)$ area 1 deleted; $(C)$ areas 1 and 2 deleted; $(D)$ areas 1 and 3 deleted; $(E)$ areas 1 and 4 deleted; and $(F)$ areas 1, 2, 3, and 4 deleted. (After Rowan and McCauley, 1966, fig. 12.)
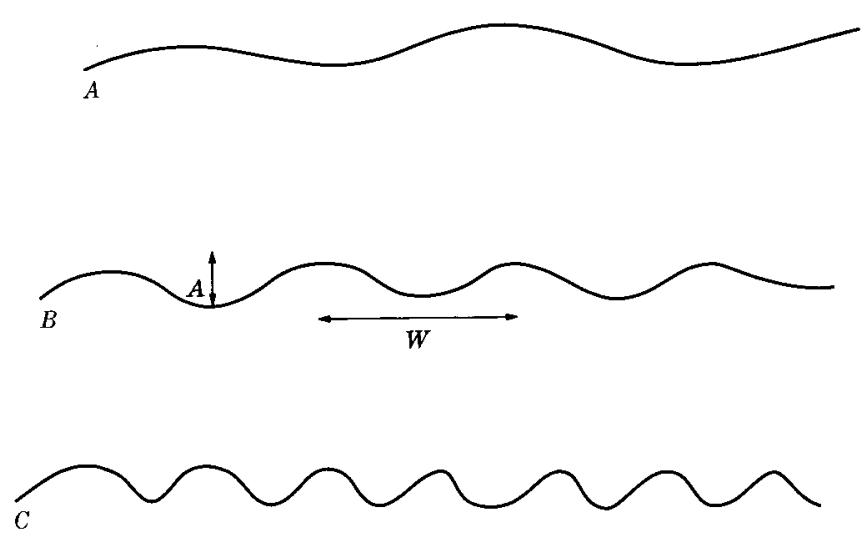

FIGURE 15.-Schematic topographic profiles showing the increasing roughness as the wavelength $(W)$ decreases and the amplitude $(A)$ increases from $A$ to $C$. be zero unless the profiles are tilted or the topography is markedly asymmetric. The algebraic standard deviation, $\sigma_{\mathrm{Al}}$, a measure of dispersion of the algebraic slope-frequency distribution, increases progressively as the slope increases in the profiles. In terrain more complex and diversified than that represented by these schematic profiles, no single statistical value obtained at a constant sample cell length appears to adequately express relative-roughness differences, and combinations of various parameters are required. Although the absolute arithmetic mean, $X_{\mathrm{Ab}}$, describes the average slope, the algebraic standard deviation, $\sigma_{\mathrm{Al}}$, is needed to express the diversity of the slopes, and the texture of the terrain is best described by the percentage of slope reversal.

The usefulness of slope-component statistics as 
relative-roughness indicators is demonstrated by analysis of the Schröter F area, which contains both terra and mare. Six terrain samples were delineated (fig. 16) by inspection prior to photoclinometric sampling. Comparison of the $\bar{X}_{\mathrm{Ab}}, \sigma_{\mathrm{Al}}$, and percentage of

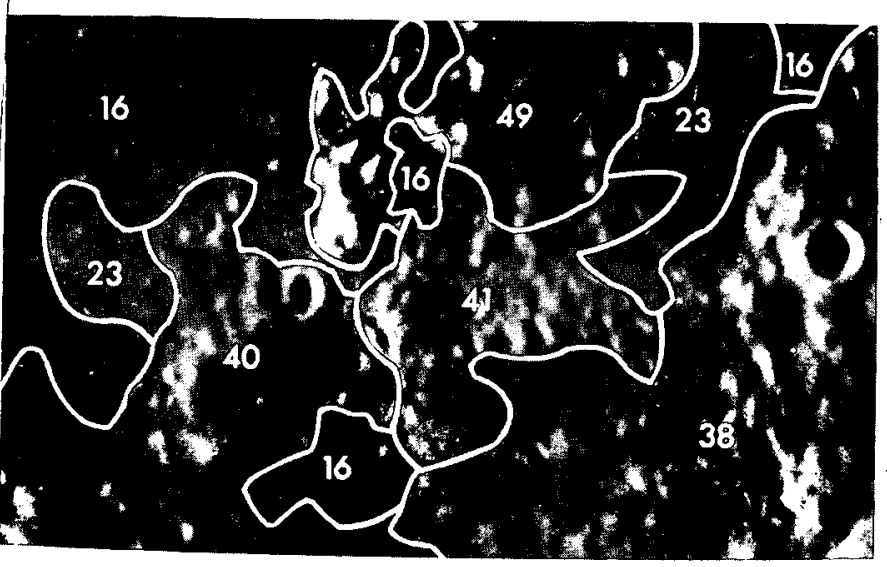

FIGURE 16.-The Schröter F area-samples 16, 23, 38, 40, 41, and 49-showing the boundaries of the slope-component samples and the morphologic types plotted on a telescopic photograph (Pease No. 124, Mount Wilson Observatory). (After Rowan and McCauley, 1966, fig. 7.)

slope reversal shows that sample areas 16 and 23 are very similar, as are areas 40,41 , and 49 , and area 49 is obviously the roughest. If prior qualitative analysis of the terrain had not been made, these distinctions would have been masked (tables 3 , total area), because more than one slope-component population would have been included in the sample.

To gain a better appreciation of the significance of central tendency slope-component values over varying slope lengths, slope studies of three mountainous terrestrial areas were made. Selection was based in part on the availability of good topographic maps at increasing scales and on general randomness of slope direction, as expressed by a predominantly dendritic drainage pattern. The Sierra Nevada-Tuolumne Meadows area in Yosemite Park, Calif., the San Juan Mountain area north of Durango, Colo., and the Mogollon Rim region between McNary and Payson, Ariz., were studied at three scales: 1:1,000,000 (Aeronautical Chart and Infor- mation Center map), $1: 250,000$. (Army Map Service map), and 1:62,500 (U.S. Geological Survey map). In each region, slope components were measured at slope lengths of $1.0,0.25$, and $0.06 \mathrm{~km}$. Only alternate slope-component segments were used to simulate as closely as possible the sampling procedure used in the microphotometer. The data were then aranged in cumulative frequency diagrams (fig. 17) for comparison with lunar slope-component data used in the early phase of this study. At the $1: 1,000,000$ scale (slope length $=1 \mathrm{~km}$ ), the median slopecomponent values of these samples of rough mountainous terrestrial terrain range from $2.5^{\circ}$ to $4.0^{\circ}$ (fig. 17A). At larger scales, however, the median increases. For example, at a slope length of 0.25 $\mathrm{km}$ the median for the for the Sierra Nevada sample is $6.0^{\circ}$ (fig. $17 B$ ), and at $0.06 \mathrm{~km}$ it is $8.5^{\circ}$ (fig. $17 C$ ). Absolute median slope-component values for the lunar terrain samples are listed in table 2 for comparison with these terrestrial values.

Three relationships that bear on the general problem of terrain roughness emerge from these terrestrial studies. First, the measurable roughness clearly is dependent on the length or the interval over which slope or any other topographic property is measured. The limiting slope length used for sampling purposes is clearly a function of the resolution of the photography employed or the resolution of the topographic map from which slope data are derived. Second, as resolution increases, the roughness, as expressed by central tendency values or other slope statistics, also increases. Third, and most significant, low statistical slope parameters over long slope lengths do not mean that these surfaces are necessarily smooth at larger scales. The surfaces may contain many locally smooth areas at larger scale, but the statistical roughness for the entire area sampled will increase rather than decrease, at a rate characteristic of the terrain unit itself. Each terrain unit may also be categorized by its own distinctive rate of increase of roughness with increasing resolution. A further discussion of this problem is contained under "Extrapolation techniques."

TABLE. 3. Slope-component statistics for sample areas in the multimorphic Schröter F area

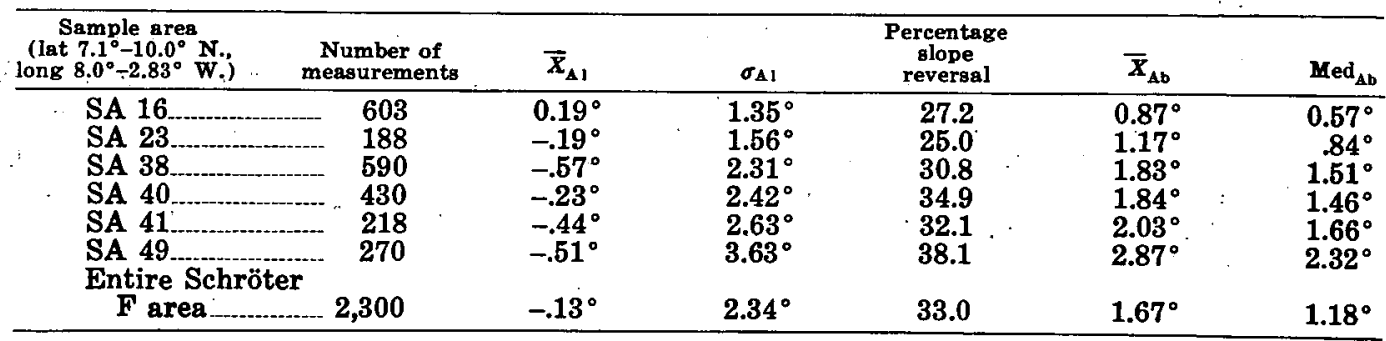



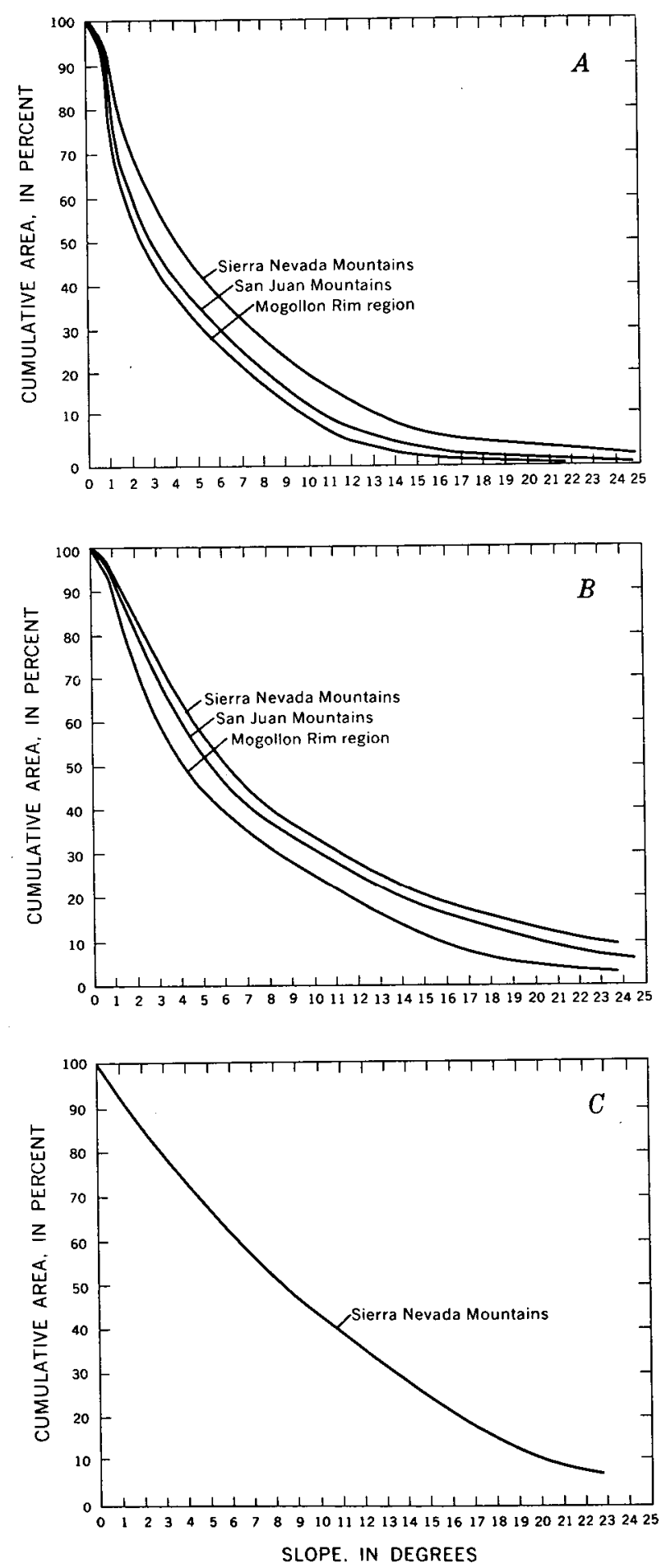

FIgURE 17.-Cumulative slope-frequency distribution curves for rough terrestrial terrain measured at varying scales: $A, 1: 1,000,000,1.0-\mathrm{km}$ slope length; $B, 1: 250,000,0.25-\mathrm{km}$ slope length; and $C, 1: 62,500$, 0.06-km slope length. (After McCauley, 1964, fig. 11.)

\section{RELATIVE-ROUghNESS PARAMETERS}

To evaluate the relative roughness of the major $1: 1,000,000$-scale lunar terrain units at earth-based resolutions, the absolute arithmetic mean, $\bar{X}_{\mathrm{Ab}}$, the algebraic standard deviation, $\sigma_{\mathrm{Al}}$, and the percentage of slope reversal calculated for the 51 sample areas were plotted against each other. The most useful plot appears to be $\bar{X}_{\mathrm{Ab}}$ versus $\sigma_{\mathrm{Al}}$ (fig. 18). Mare and terra divisions clearly occupy discrete zones or areas on the plot, although there is some overlap; crater components span the range of roughness from mare to rugged terra (units II-C and II-D). Of particular importance is the clearly different roughness of unconstructed smooth mare relative to mare complicated by ridges; rilles, and craters. The ranges of characteristic slope-component and relative-roughness parameters, $\bar{X}_{\mathrm{Ab}}, \sigma_{\mathrm{Al}}$, and percentage of slope reversal, are given in table 4.

According to Leone, Nelson, and Nottingham (1961), $\bar{X}_{\mathrm{Ab}}$ for "half-normal distributions" is related to $\sigma_{\mathrm{Al}}$ by

$$
\bar{X}_{\mathrm{Ab}}=\sqrt{\frac{2}{\pi} \cdot \sigma_{\mathrm{Al}} .}
$$

Although figure 18 clearly shows that the two parameters are closely related, equation 1 does not hold for the data plotted in figure 18; the $X_{\mathrm{Ab}}$ values are too low for given $\sigma_{\mathrm{Al}}$ values. An empirical expression relating these parameters for photoclinometrically derived lunar slope components was derived from figure 18:

$$
\bar{X}_{\mathrm{Ab}}=0.79 \sigma_{\mathrm{Ad}} ;
$$

$\bar{X}_{\mathrm{Ab}}$ can be estimated from equation 2 and need not be derived independently, and $\sigma_{\mathrm{Al}}$ can be used by itself as an index of relative roughness and as an expression for the rate of change of roughness as a function of scale when plotted against the sample length.

Plots of the percentage of slope reversal versus $\bar{X}_{\mathrm{Ab}}$ and $\sigma_{\mathrm{Al}}$ exhibit a large amount of scatter; thus, slope reversal may be only indirectly related to these statistical values. Slope reversal may, therefore, be a fundamental terrain classification parameter in the same sense that amplitude and frequency are critical in the definition of a periodic function.

As previously mentioned, $\bar{X}_{\mathrm{Al}}$ proved to be of little general use. Where topography is symmetrical in the east-west direction and there is no censoring because of shadowing effects, $\bar{X}_{\mathrm{Al}}$ will be close to zero. A significant departure from zero in the absence of the above effects, however, is a measure of the regional slope, which is almost impossible to detect by qualitative study of the lunar plates. Thus, $\bar{X}_{\mathrm{Al}}$ has local significance. In areas where regional slopes are 
TABLE 4.-Limiting relative-roughness values for major terrain units in the lunar equatorial zone

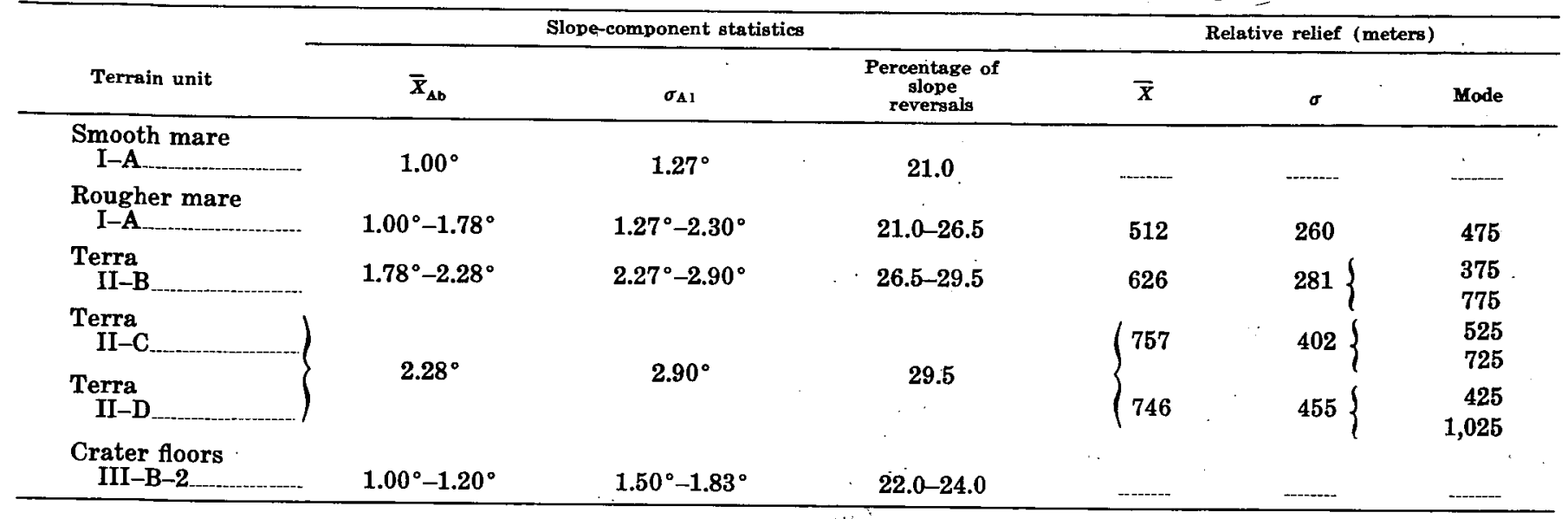

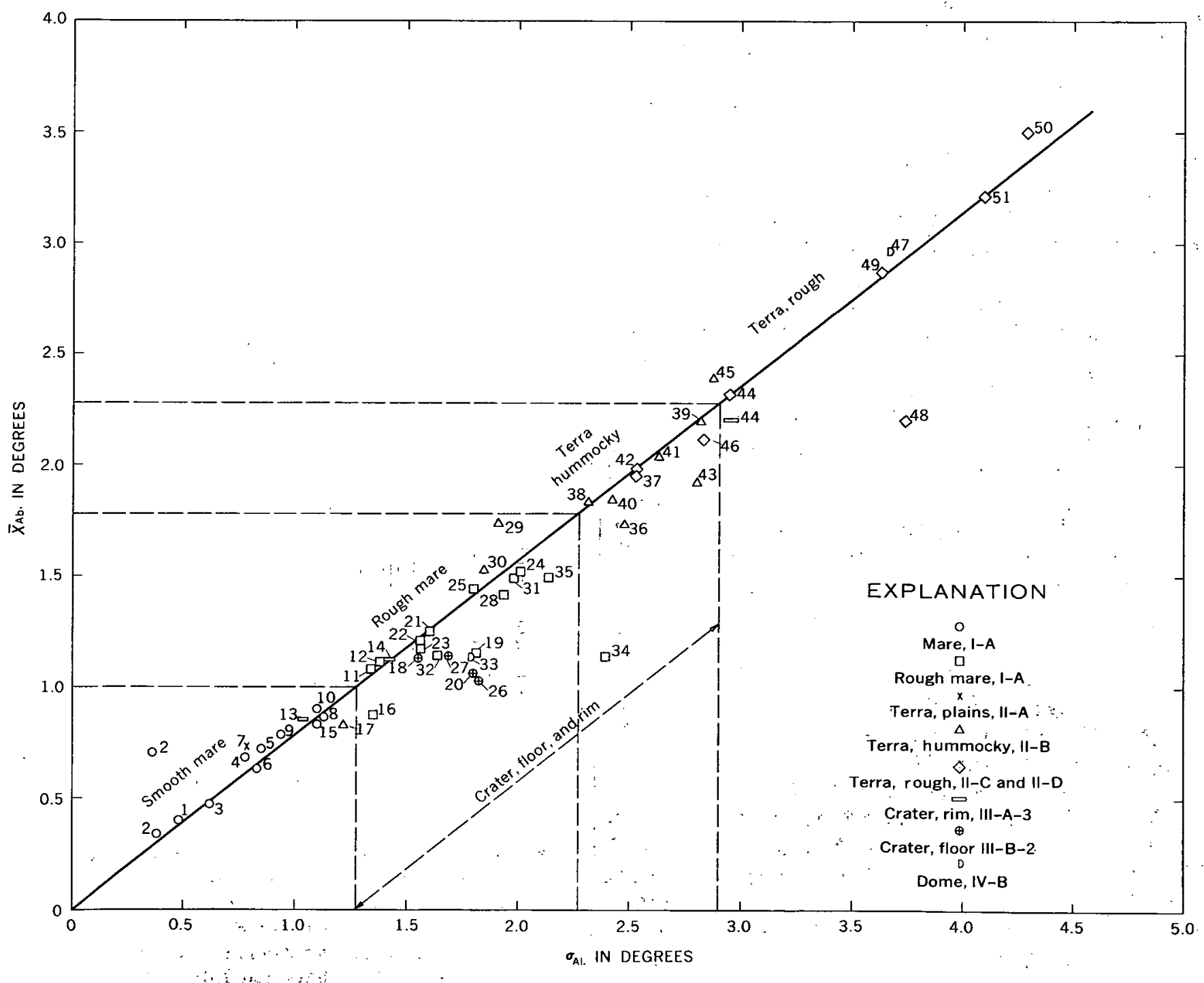

FIGURE 18.-Plot of the algebraic standard deviation, $\sigma_{\mathrm{Al}}$, versus the absolute arithmetic mean, $\bar{X}_{\mathrm{Ab}}$, for the 51 slope-component sample areas showing the range of the major lunar terrain types. 
greater than $1^{\circ}, \bar{X}_{\mathrm{Al}}$ has been adjusted to zero in table 2 , so that $\bar{X}_{\mathrm{Ab}}$ is not affected.

Because of the previously described difficulties in obtaining dependable slope-component measurements in relatively rough areas, relative-relief statistics were used as supplemental means of describing relative roughness in the lunar terra. Approximately 1,200 measurements, for sample lengths ranging from 3 to $5 \mathrm{~km}$, were statistically analyzed for the three roughest terra units, II-B, II-C, and II-D, and rougher mare, I-A. The measurements were furnished by the Air Force Chart and Information Center, St. Louis, Mo. Table 4 gives the most useful relative-relief statistical parameters for the terrain types where data were available, and the frequency distributions are shown in figure 19. These distributions are all bimodal, suggesting that the measurements were made on at least two distinct terrain populations. The terra areas in the equatorial zone are commonly a composite of several types of terrain consisting of (1) rugged hills and intervening valleys of structural origin, (2) hummocky to braided terrain related presumably to the Imbrium event, and (3) superimposed old and young craters. Relativerelief data clearly discriminate hummocky terra, II-B, from the more rugged sculptured terra, II-C and II-D. Effective detailed quantitative classification is, however, difficult owing to this morphologic heterogeneity. During regional mapping of these terrain types, qualitative estimates of relative roughness had to be relied upon.

Different empirical combinations of these basic relative-roughness parameters can be used to classify lunar terrain in terms of suitability for mobility and landing. For example, in considering a landing site, roughness classification might be weighted in favor of the frequency data because numerous abrupt slope reversals in any area would present a severe hazard. On the other hand, if mobility were the prime consideration, the classification might be weighted in favor of the standard deviation, a measure of terrain diversity; a high standard deviation would indicate the presence of numerous areas of extreme slope that could not be traversed.

\section{EXTRAPOLATION TECHNIQUES}

The rate of change of roughness, as defined by one or more terrain parameters plotted as a function of the size of the sample cell $(\Delta L)$, appears to be of value for limited extrapolation of terrain characteristics below the resolution of particular photographs. It may be distinctive for various units, and for topography characterized by increasingly smaller craters of the same forms, may remain constant over a

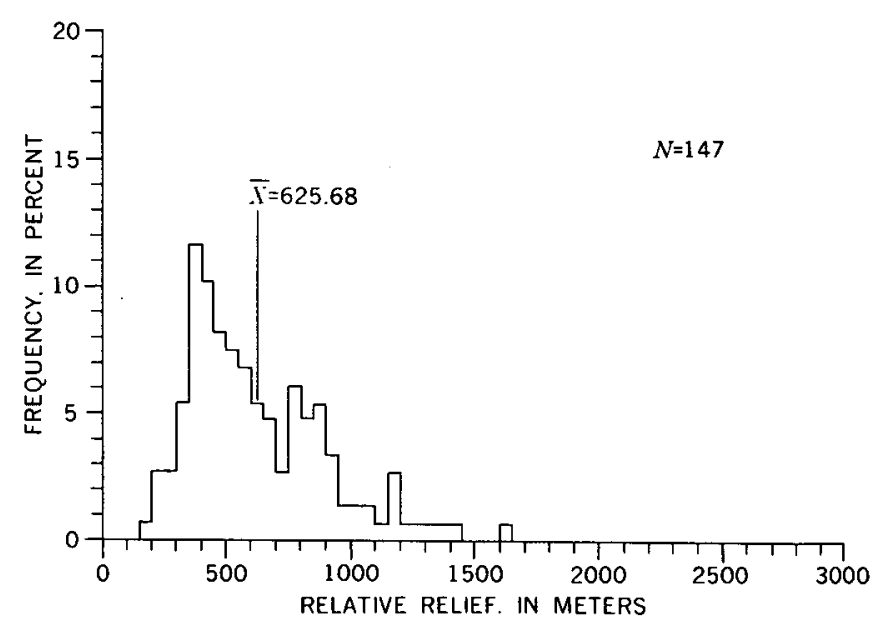

$A$

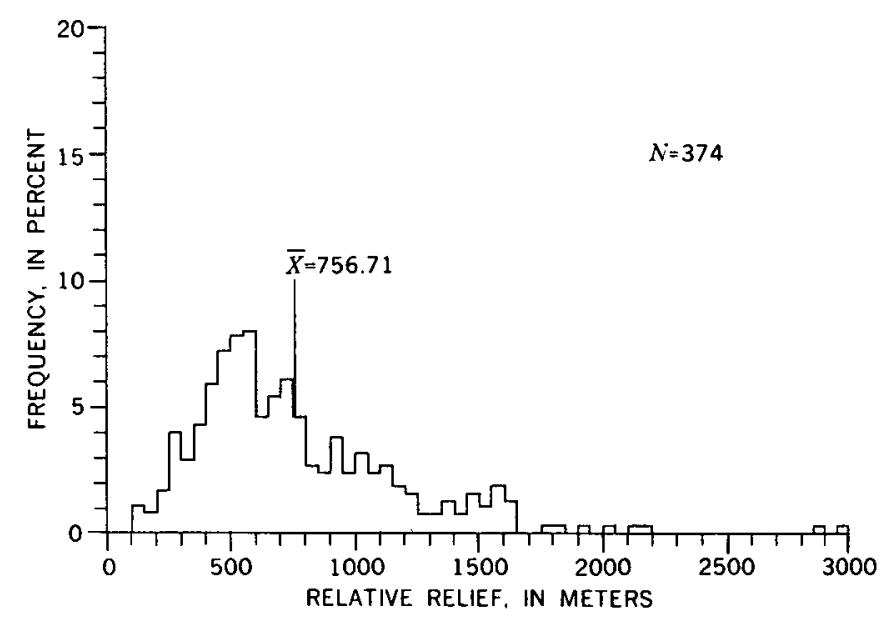

$B$

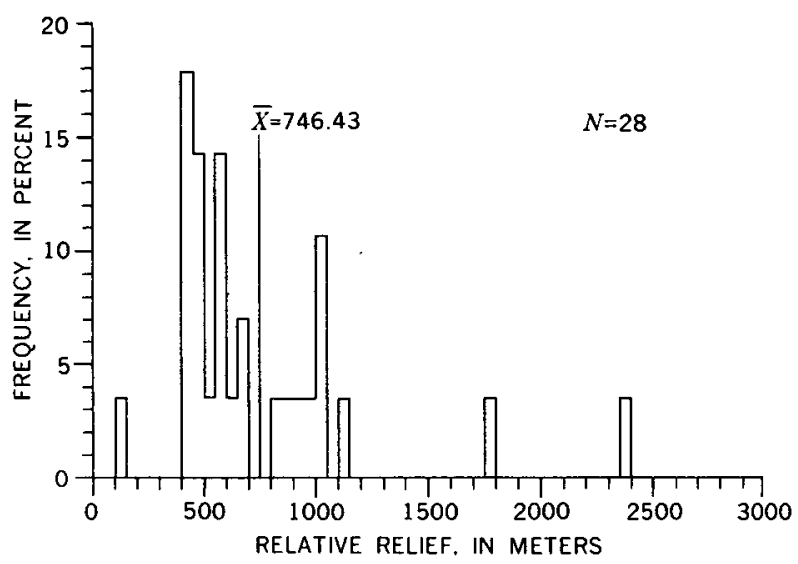

C

FIGURE 19.-Relative-relief frequency histograms for $A$, hummocky terra, II-B; $B$, hummocky terra with moderate relief, II-C; and $C$, sculptured terra with moderate to high relief, II-D. $N$ is the number of measurements. Measurements made over 3-5 $\mathrm{km}$ horizontal distances by the U.S. Air Force Chart and Information Center, St. Louis, Mo., using the shadow technique. (After Rowan and McCauley, 1966, fig. 14.) 
wide range of resolutions. Other areas photographed under progressively higher resolution will show inflection points in the curve as new types of terrain features, such as large blocks, are resolved.

This extrapolation technique was used to predict the mean slope of typical maria at the 1-meter scale from earth-based observations prior to the flight of Ranger VII (McCauley, 1964). Figure 20 shows that ers (1965) as 1-meter $\Delta L$. They are very similar to the parameters and curves for terra at the $1-\mathrm{km}$ scale or resolution (table 2 ; figs. 12, 18). Statistics derived from the original photometric scans and those from the map are not, however, strictly comparable.

Although few other data points are currently available, it appears that predictive techniques might

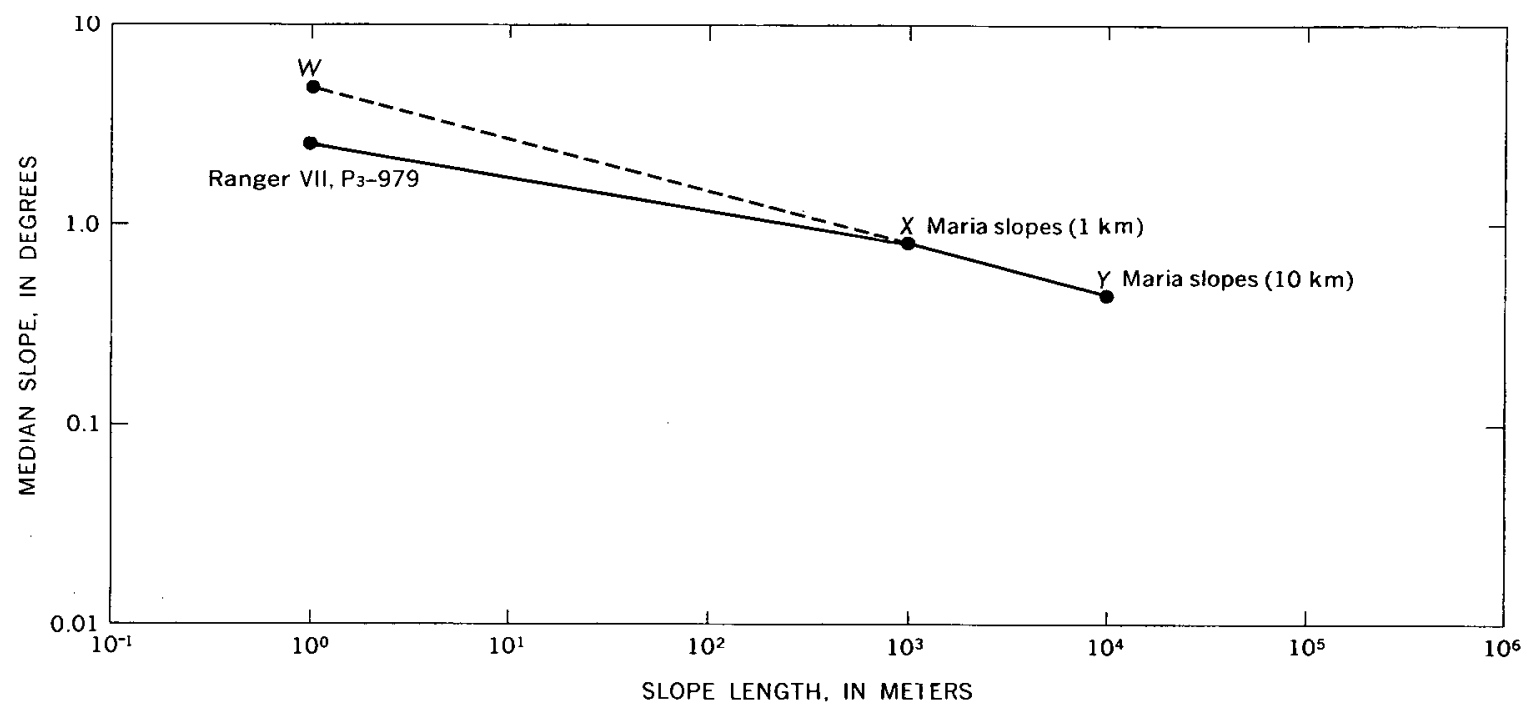

FIGURE 20.-Extrapolation of median slope to the 1-meter scale from telescopic data for mare terrain. The segment $W X$ represents extrapolation prior to receipt of Ranger VII data. Curves for each distinctive terrain unit should show a different slope. (After McCauley, 1964, fig. 14; and Rowan and McCauley, 1966, fig. 15.)

the median slope-component value at the 1-meter scale (about $3.6^{\circ}$ ), derived from the original photometric scans of the last Ranger VII frame $\left(\mathrm{P}_{3}-979\right)$, falls near a straight-line extrapolation of median slopes over $1.0 \mathrm{~km}$ and longer slope lengths (Rowan and McCauley, 1966).

Figure 21 gives the statistical relative-roughness parameters $\bar{X}_{\mathrm{Ab}}$ and $\sigma_{\mathrm{Al}}$ and slope frequency curve derived from analysis of profiles of the map prepared of the last Ranger VII frame by Shoemaker and oth- be further developed by examining the functional relations between $\Delta L$ and other statistical values such as crater density, relative-relief data, slope reversal, and power spectral data for a variety of lunar terrain types. Wood and Snell (1959) investigated the use of a ranking method of correlation for six terrain factors from 200 samples in the United States. Average large-scale slope could be predicted from small-scale relief maps with an error of 4 percent for the smoother parts of the United States.

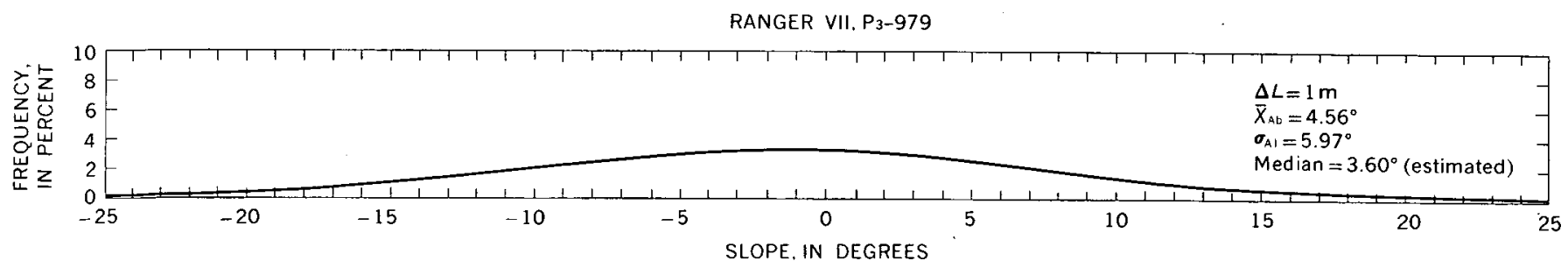

FIGURE 21.-Algebraic slope-component frequency distribution curve and statistical parameters for Ranger VII photograph $P_{3}-979$ of an area in Mare Cognitum. (After Rowan and McCauley, 1966, fig. 16.) 
Using curvature rather than slope measurements, personnel at the Bendix Systems Division (1965) also demonstrated the relations between $\Delta L$ and roughness. Once the effect of resolution $(\Delta L)$ on the statistical parameters of particular lunar terrain units is established, large-scale surface properties may be predictable with a fair degree of accuracy if the terrain unit can be identified in lower resolution photography. Lunar Orbiter monoscopic 1-3meter resolution photographs of many terrain types are now available, and 60-90-meter resolution photographs of nearly all the lunar surface are also available. Although a large sampling program will be required, nomograms can be constructed for most terrain units to permit the prediction of relative roughness in areas not covered by 1-3-meter resolution photographs. The data that can be obtained by terrain extrapolation techniques could be very useful for planning future planetary exploration missions; the techniques, therefore, deserve additional study.

\section{APPLICATIONS TO SPACECRAFT TARGETING}

As previously mentioned, the primary objectives of the lunar terrain analysis program were to classify and rank terrain in the equatorial zone according to relative roughness so that the results could be applied to site-selection studies for the Ranger, Surveyor, Lunar Orbiter, and Apollo missions. During the latter stages of the program a rationale was developed for the selection of photographic targets and landing sites. Essential to this rationale were data on the relative roughness of the major terrain units in the equatorial zone and an appreciation for the predictable greater roughness with increasing resolution. When statistical relative-roughness data for a potential landing site can be extrapolated from low-resolution data, the relative probability of a successful landing can be predicted. In addition, data from landed spacecraft can be extrapolated to a potential landing site, if similar terrain types occur there. It is impossible, however, to determine in advance whether unresolved hazards exist at a particular' point.

The successful Ranger experiments, VII, VIII, and IX, obtained nested, increasing-resolution television images of two widely separated maria and the floor of a modified terra crater. Results of the terrain analysis studies were used in the selection of the Ranger VII and Ranger VIII targets. The selected aim point for Ranger VII was long $20^{\circ} \mathrm{W}$. and lat $11^{\circ} \mathrm{S}$., in the unnamed mare between Mare Nubium and Oceanus Procellarum (this area was later named Mare Cognitum in recognition of the success of Ranger VII). This first view of the moon at the 1-meter scale provided by Ranger VII indicated that its surface, although heavily cratered, was probably smooth enough for spacecraft landings. Ranger VIII was successfully deployed to photograph a small area in Mare Tranquillitatis (long $24^{\circ}$ E., lat $3^{\circ} \mathrm{N}$.) . Ranger IX was sent to the floor of the terra crater Alphonsus mainly to gather data on an area in which transient activity had been reported and also to photograph terra basin materials.

The Ranger spacecraft, in addition to providing views of very small areas on the moon at a resolution of about a meter, were important because they provided continuous variable-scale imagery that bridged the gap between earth-based telescopic resolution and the type of large-scale data needed for landingsite evaluations. The large-scale high-resolution data returned by the three Ranger spacecraft suggested that areas of the moon were sufficiently smooth at the 1-meter scale for landings. The feasibility of both the Surveyor and Apollo programs was thus partially demonstrated. The principal task of the Lunar Orbiter and Surveyor missions was to extend the highresolution Ranger coverage and thereby provide the basis for certifying an array of equatorial sites suitable for manned landings.

\section{SURVEYOR}

Prior to the launch of Surveyor I, 65 candidate landing sites were selected (McCauley and others, 1966) on the basis of telescopic observations and photographs, terrain and geologic maps, the statistical relative-roughness data reported herein, and the results of analyses of the Ranger VII and VIII photographs.

The rationale for the selection of these landing sites was based on various spacecraft engineering constraints, scientific merits, and terrain roughness. The 65 sites were also rated by a partially quantitative technique to facilitate final value judgments whereby the engineering, scientific, and site suitability considerations were traded off against one another.

\section{LUNAR ORBITER}

The Lunar Orbiter spacecraft were designed to photograph potential landing areas for Surveyor and Apollo. Each of the five spacecraft was equipped with -a dual-lens camera capable of obtaining monoscopic 1-meter and stereoscopic 8-meter resolution photographs from a perilune altitude of approximately $50 \mathrm{~km}$.

Planning the photographic tasks of the Lunar Orbiter missions was a complicated undertaking because of lighting, exposure, and readout problems. The specific requirements of the Surveyor and Apollo 
programs for the best possible photography of potential landing areas near the equator further restricted targeting capability. At the time of initial planning for Orbiter I, the only photography available with resolution greater than about $0.5 \mathrm{~km}$ was that obtained by Rangers VII, VIII, and IX and Surveyor I. Although of great scientific and engineering value, the high-resolution photographic coverage of these experiments was very limited in areal extent. Moreover, the area photographed by Rangers VII and IX were, for the most part, outside of the equatorial zone. Therefore, during mission planning activities extensive use was made of the $1: 1,000,000$ scale terrain map (Rowan, 1966; Holm and others, 1965) and the lunar geologic maps then available.

Most of the major terrain types in the equatorial zone were photographed during the first Orbiter mission, including the dark maria, all four types of terra, and modified and well-formed craters. Detailed terrain maps of each of nine prime sites to be photographed by Lunar Orbiter I were prepared just prior to the mission and used during the mission for locating more precisely the desired photographic coverage. (See U.S. Geol. Survey, 1966.) Each succeeding mission plan incorporated the results of evaluation of the preceding missions, but as new sites were selected, the 1:1,000,000-scale terrain and geologic maps continued to be used in the siteselection process.

Because the high-resolution camera of Orbiter I failed early in the mission, the two successive Orbiters were also devoted almost exclusively to the landing-site search. Elimination of large tracts of the equatorial belt based on terrain consideration facilitated effective completion of the site-search role prior to Orbiter IV. The last two missions could be devoted, therefore, to gathering new scientific data, first by means of Orbiter IV's planetwide coverage of most of the lunar surface at an average resolution of 80 meters and later by Orbiter V's detailed 2-meter photography of sites of particular scientific interest.

\section{SUMMARY}

Results of the lunar terrain analysis program were as follows: (1) Lunar equatorial terrain was classified and terrain maps weie prepared at $1: 2,000,000$ and $1: 1,000,000$ scales, (2) relativeroughness indicators were derived through statistical analysis of relative-relief data and some 150,000 slope-component measurements at $0.75-\mathrm{km}$ slope lengths made during this study, (3) the usefulness of algebraic slope-frequency distributions was dem- onstrated at telescopic resolutions, and (4) relative roughness of mare surfaces at small slope lengths was extrapolated from roughness data for larger slope length, and thereby the utility of the technique for future landing and trafficability studies was demonstrated. In addition, the photoclinometric technique was refined and automated for slope measurements from telescopic photographs so that enough measurements were available for valid statistical analysis. Perhaps the most promising aspect of these results is the application of the extrapolation techniques to quantitative description of terrain and geologic units.

These results have been applied to site-selection studies for the photographic Ranger and Lunar Orbiter missions and for Surveyor and Apollo landings. Much of the rationale developed in the siteselection studies could be applied to the exploration of other terrestrial planetary surfaces.

\section{SELECTED REFERENCES}

Chief of Engineers, Department of Army, 1958, Terrain study of Fort Benning and vicinity: Engineer Intelligence Study 211, 79 p.

Bendix Systems Division, 1965, Bi-parameter universal random surface: Rept. BSR 1082, Ann Arbor, Michigan, p. 1-33.

Blackman, R. B., and Tukey, J. W., 1958, The measurement of power spectra: New York, Dover Pubs., Inc., 190 p.

Diggelen, J. van, 1951, A photometric investigation of the slopes and heights of the ranges and hills in the maria of the moon: Astron. Inst. Netherlands Bull., v. 11, p. 283-289.

Hackman, R. J., and Mason, A. C., 1961, Engineer special study of the surface of the moon: U.S. Geol. Survey Misc. Geol. Inv. Map I-351.

Hammond, E. H., 1964, Analysis of properties in landform geographies, Assoc. Am. Geographers Annals, v. 54, p. 11-23.

Hawkins, J. K., and Munsey, C. J., 1963, Automatic photo reading: Photogramm. Eng., v. 29, no. 4, p. 632-640.

Halm, E. A., Rowan, L. C., and McCauley, J. F., 1965, Terrain atlas of the lunar equatorial belt: U.S. Geol. Survey openfile report [1969].

Kopal, Zdĕnek, 1962, Topography of the moon in Kopal Zdĕnek, ed., Physics and astronomy of the moon: London, Academic Press, p. 251-282.

Kuiper, G. P., ed., 1960, Photographic lunar atlas: Chicago, Univ. Chicago Press.

- 1961, Orthographic atlas of the moon, supp. 1 to Photographic lunar atlas: Tucson, Univ. Arizona Press.

Leone, F. C., Nelson, L. S., and Nottingham, R. B., 1961, The folded normal distribution: Technometrics, v. 3 , no. 4, p. $543-550$.

Lindgren, B. W., and McElrath, G. W., 1959, Introduction to probability and statistics: New York, Macmillan Co., $253 \mathrm{p}$.

McCauley, J. F., 1964, A preliminary report on the terrain analysis of the lunar equatorial belt: U.S. Geol. Survey open-file report, 44 p. [1965]. 
1965, Slope frequency distributions as a means of classifying lunar terrain in Abstracts for 1964: Geol. Soc. America Spec. Paper 82, p. 130.

McCauley, J. F., Holt, H. E., Morris, E. C., O'Connor, J. T., Rowan, L. C., and Filice, Alan, 1966, Surveyor landing site recommendations in Lunar Orbiter-Image Analysis Studies Report, May 1, 1965 to January 31, 1966: U.S. Geol. Survey open-file report, p. 49-66.

Minnaert, M., 1961, Photometry of the moon in Kuiper, G. P., and Middlehurst, B. M., eds., Planets and satellites, v. 3 of The solar system: Chicago, Univ. Chicago Press, p. 213-245.

Pike, R. J., 1968, Meteoritic origin and consequent endogenetic modification of large lunar craters-A study in analytical geomorphology: U.S. Geol. Survey open-file report, $404 \mathrm{p}$.

Rowan, L. C., 1966, Recommendations for Lunar Orbiter Mission A in Lunar Orbiter-Image Analysis Studies Report, May 1, 1965 to January 31, 1966: U.S. Geol. Survey openfile report, p. 67-69.

Rowan, L. C., and McCauley, J. F., 1966, Lunar terrain analysis in Lunar Orbiter-Image Analysis Studies Report, May 1, 1965 to January 31, 1966: U.S. Geol. Survey openfile report, p. 89-127.

Rowan, L. C., and West, Mareta, 1966, A preliminary albedo map of the lunar equatorial belt in Lunar Orbiter-Image Analysis Studies Report, May 1, 1965 to January 31, 1966: U.S. Geol. Survey open-file report, p. 71-83.

Rozema, Wesley, 1968, The use of spectral analysis in describing lunar surface roughness: U.S. Geol. Survey open-file report, 35 p. [1969].

Shoemaker, E. M., and others, 1965, Topographic model of a small area of the moon's surface in Mare Cognitum: U.S. Army Corps of Engineers, Special Map.

Strahler, A. M., 1950, Equilibrium theory of erosional slopes approached by frequency distribution analysis: Am. Jour. Sci., v. 248 , p. 673-696, 800-814.

- 1954, Statistical analysis in geomorphic research: Jour. Geology, v. 62, no. 1, p. 1-25.

1956, Quantitative slope analysis: Geol. Soc. America Bull., v. 67, p. 571-596.

U.S. Geological Survey, 1966, Space flight investigations, pt. D of Astrogeologic Studies Ann. Prog. Rept., July 1, 1965 to July 1, 1966: U.S. Geol. Survey open-file report, $70 \mathrm{p}$. [1968].

1968, National atlas of the United States, sheets 61-64, Classes of Land-surface form; sheet 59, Physiography and physiographic divisions.

Watson, Kenneth, 1968, Photoclinometry from spacecraft images: U.S. Geol. Survey Prof. Paper 599-B, 10 p.

Whitaker, E. A., Kuiper, G. P., Hartmann, W. K., and Spradley, L. H., eds., 1963, Rectified lunar atlas, supp. 2 to Photographic lunar atlas: Tueson, Univ. Arizona Press, $30 \mathrm{p}$.

Wilhelms, D. E., 1964, A photometric technique for measurements of lunar slopes in Astrogeologic Studies Ann. Prog. Répt., August 25, 1962 to July 1, 1963, pt. D: U.S. Geol. Survey open-file report, p. 1-12.

_ 1970, Summary of lunar stratigraphy-telescopic observations: U.S. Geological Survey Prof. Paper 599-F, $47 \mathrm{p}$.

Wood, W. F., and Snell, J. B., 1959, Predictive methods in topographic analysis, 1, Relief, slope and dissection in inch-to-the-mile maps in the United States: Headquarters, Quartermaster Research and Eng. Command, U.S. Army, Tech. Rept. EP-112, p. 1-31.

\section{LUNAR GEOLOGIC MAP REFERENCES ${ }^{\circledR}$}

Eggleton, R. E., 1965, Geologic map of the Riphaeus Mountains region of the Moon: U.S. Geol. Survey Misc. Geol. Inv. Map. I-458 (LAC 76).

Elston, D. P., 1965, Preliminary geologic map of the Colombo quadrangle of the Moon (LAC 79) in Astrogeologic Studies Ann. Prog. Rept., July 1, 1964 to July 1, 1965, map supp.: U.S. Geol. Survey open-file report [1966].

Hackman, R. J., 1962, Geologic map and sections of the Kepler region of the Moon: U.S. Geol. Survey Misc. Geol. Inv. Map I-355 (LAC 57, 2d ed., 1962).

Howard, K. A., and Masursky, Harold, 1968, Geologic may of the Ptolemaeus quadrangle of the Moon: U.S. Geol. Survey Misc. Geol. Inv. Map I-566 (LAC 77).

Marshall, C. H., 1963, Geologic map and sections of the Letronne region of the Moon: U.S. Geol. Survey Misc. Geol. Inv. Map I-385 (LAC 75, 2d ed., 1962).

Masursky, Harold, 1965, Preliminary geologic may of the Mare Undarum quadrangle of the Moon (LAC 62) in Astrogeologic Studies Ann. Prog. Rept., July 1, 1964 to July 1, 1965, map supp.: U.S. Geol. Survey open-file report [1966].

McCauley, J. F., 1964, Preliminary geologic may of the Grimaldi quadrangle of the Moon (LAC 74) in Astrogeologic Studies Ann. Prog. Rept., July 1, 1963, to July 1, 1964, map supp.: U.S. Geol. Survey open-file report [1965].

1967, Geologic map of the Hevelius region of the Moon: U.S. Geol. Survey Misc. Geol. Inv. Map I-491 (LAC 56).

Milton, D. J., 1964, Preliminary geologic map of the Theophilus quadrangle of the Moon (LAC 78) in Astrogeologic Studies Ann. Prog. Rept., July 1, 1963 to July 1, 1964, map supp.: U.S. Geol. Survey open-file report [1965].

Moore, H. J., 1967, Geologic map of the Seleucus quadrangle of the Moon: U.S. Geol. Survey Misc. Geol. Inv. Map I-527 (LAC 38).

Morris, E. C., and Wilhelms, D. E., 1967, Geologic map of the Julius Caesar quadrangle of the Moon: U.S. Geol. Survey Misc. Geol. Inv. Map I-510 (LAC 60).

Schmitt, H. H., Trask, N. J., and Shoemaker E. M., 1967, Geologic map of the Copernicus quadrangle of the Moon: U.S. Geol. Survey Misc. Geol. Inv. Map I-515 (LAC 58, 2d ed., 1964).

Titley, S. R., 1967, Geologic map of the Mare Humorum region of the Moon: U.S. Geol. Survey Misc. Geol. Inv. Map I-495 (LAC 93).

Wilhelms, D. E., 1965, Preliminary geologic map of the Taruntius quadrangle of the Moon (LAC 61) in Astrogeologic Studies Ann. Prog. Rept., July 1, 1964 to July 1, 1965, map supp.: U.S. Geol. Survey open-file report [1966].

1968, Geologic map of the Mare Vaporum quadrangle of the Moon: U.S. Geol. Survey. Misc. Geol. Inv. Map I-548 (LAC 59).

Wilhelms, D. E., and Ryan, J. D., 1965, Preliminary geologic map of the Langrenus quadrangle of the Moon (LAC 80) in Astrogeologic Studies Ann. Prog. Rept., July 1, 1964 to July 1, 1965, map supp.: U.S. Geol. Survey open-file report [1966].

Wilhelms, D. E., and Trask, N. J., 1965, Preliminary geologic map of the equatorial belt in Astrogeologic Studies Ann. Prog. Rept., July 1, 1964 to July 1, 1965, map supp. [scale $1: 5,000,000$ ] : U.S. Geol. Survey open-file report [1966].

${ }^{3} 1: 1,000,000$ scale, exceept where otherwise indicated. Numbers in parentheses are designations of $1: 1,000,000-8 \mathrm{cale}$ topographic maps prepared by U.S. Air Force Chart and Information Center, St. Louis, Mo. 
FIGURES 22-29 


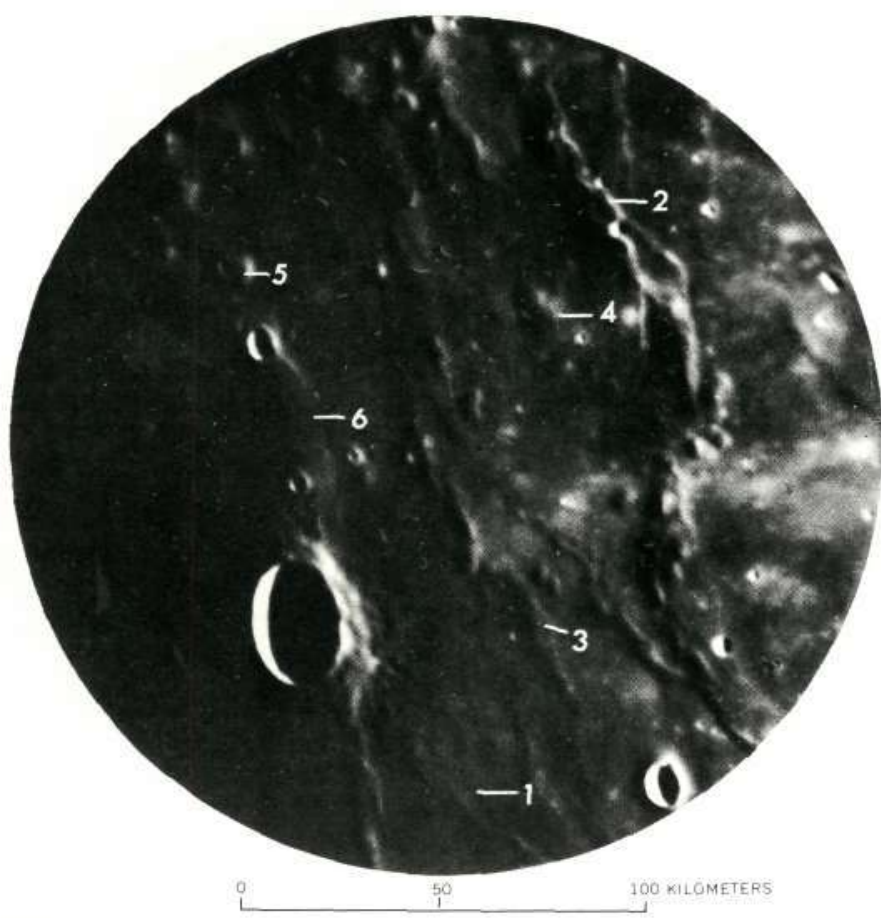

Figure 24.-Representative lunar terrain units in intermare area northwest of Fra Mauro (lat $1.5^{\circ} \mathrm{S}$., long $20^{\circ} \mathrm{W}$.; Mount Wilson Observatory plate Pease $124 \mathrm{C}$ ) :

Unit II-B. Hummocky to gently rolling terrain typical of much of region surrounding Mare Imbrium (1); slopes about $5^{\circ}$ on flanks of hummocks or linear hills.

Unit III-A. Sharp unmodified crater (2).

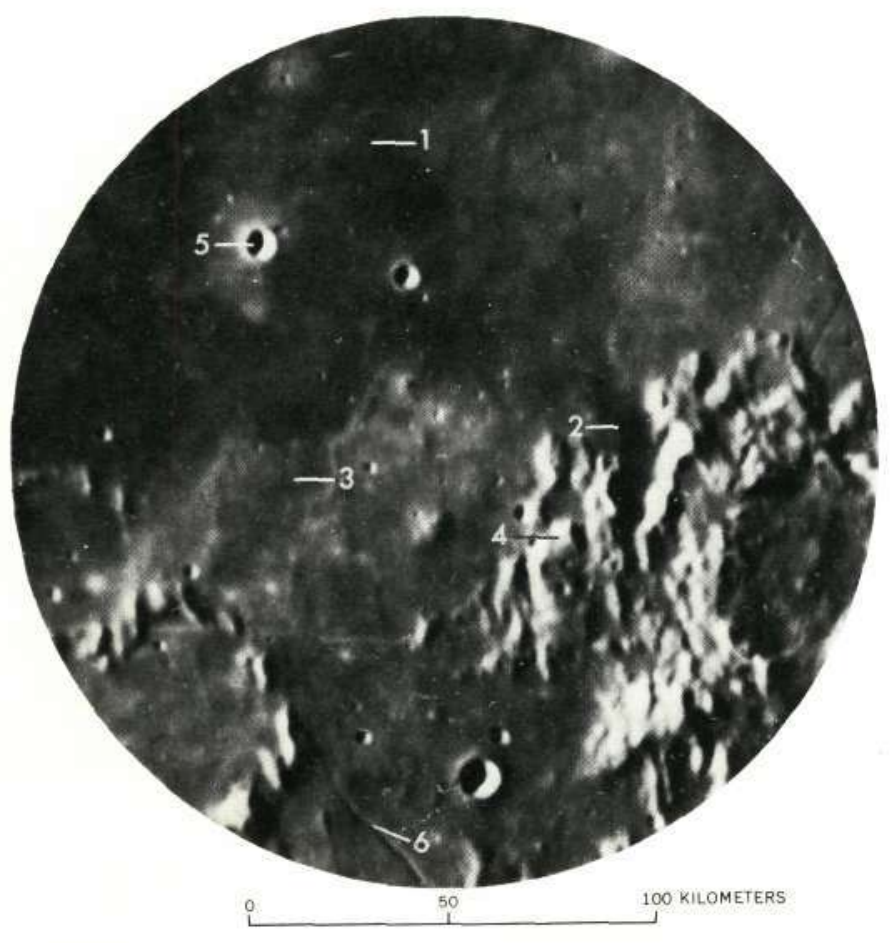

4 Figure 22-Representative lunar terrain units in southern part of Marius Hills area near crater Reiner (lat $8^{\circ} \mathrm{N}$., long $53^{\circ}$ W.; Lick Observatory plate ECD 75).

Unit I-A. Smooth mare plains without resolvable relief (1) ; low crater density.

Unit IV-A. Asymmetrical mare ridge (2) ; smoother symmetrical mare ridge (3).

Unit IV-B. Low symmetrical dome with side slopes of several degrees and relief of about 100 meters (4); steep-sided dome with side slopes up to $10^{\circ}$ and relief of about 200 meters (5).

Unit IV-D. Broad flat-topped mare ridge or plateau bounded by gentle escarpments with slopes of several degrees (6).

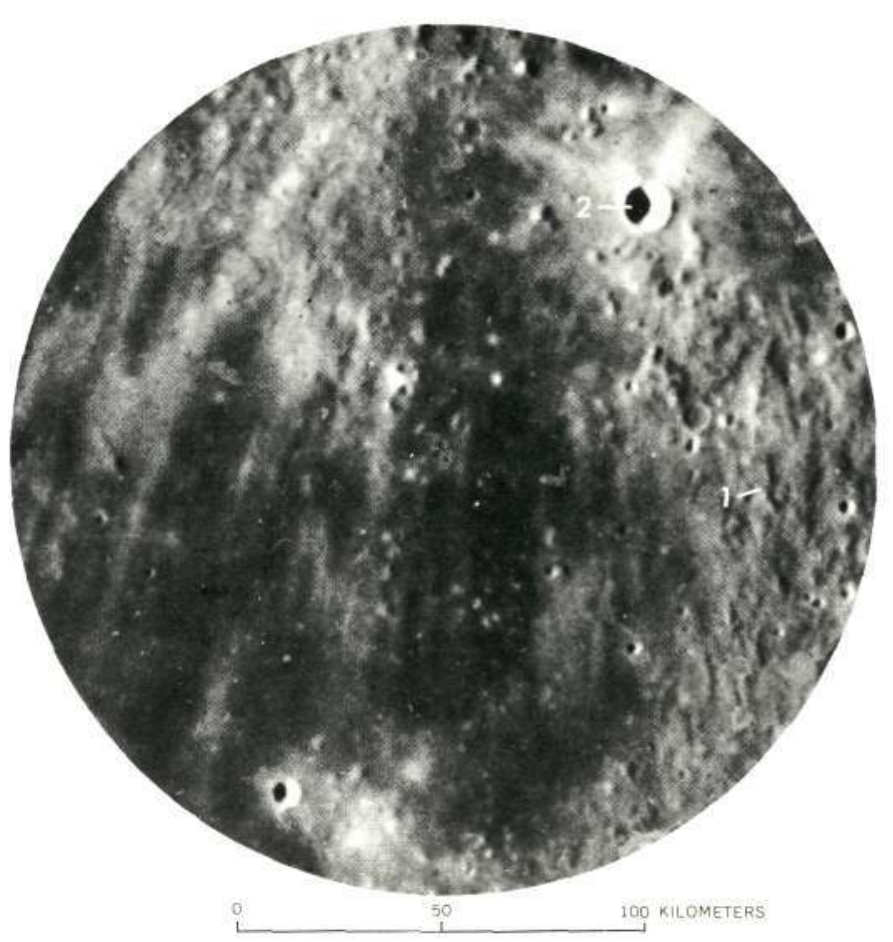

4 Figure 23.-Representative lunar terrain units in southern Sinus Medii area (lat $0^{\circ}$ N., long $2^{\circ}$ E.; Lick Observatory plate ECD 63 ).

Unit I-A. Smooth mare plains (1).

Unit I-B. Dark mare plains; few craters; no visible relief (2).

Unit II-A. Smooth terra plains; higher density in small craters than in mare units; planar to gently rolling surface (3).

Unit II-C. Blocky to lineated terra; smooth at fine scale but slopes on individual blocks about $10^{\circ}-20^{\circ}$ (4).

Unit III-A. Fresh unmodified crater; sharp rim crest; surrounded by rays; interior slopes up to $30^{\circ}$; exterior slopes on rim about $15^{\circ}(5)$.

Unit IV-C-1. Linear rilles, bounded by steep relatively straight scarps with slopes about $15^{\circ}-20^{\circ}$ (6); flat floors. 


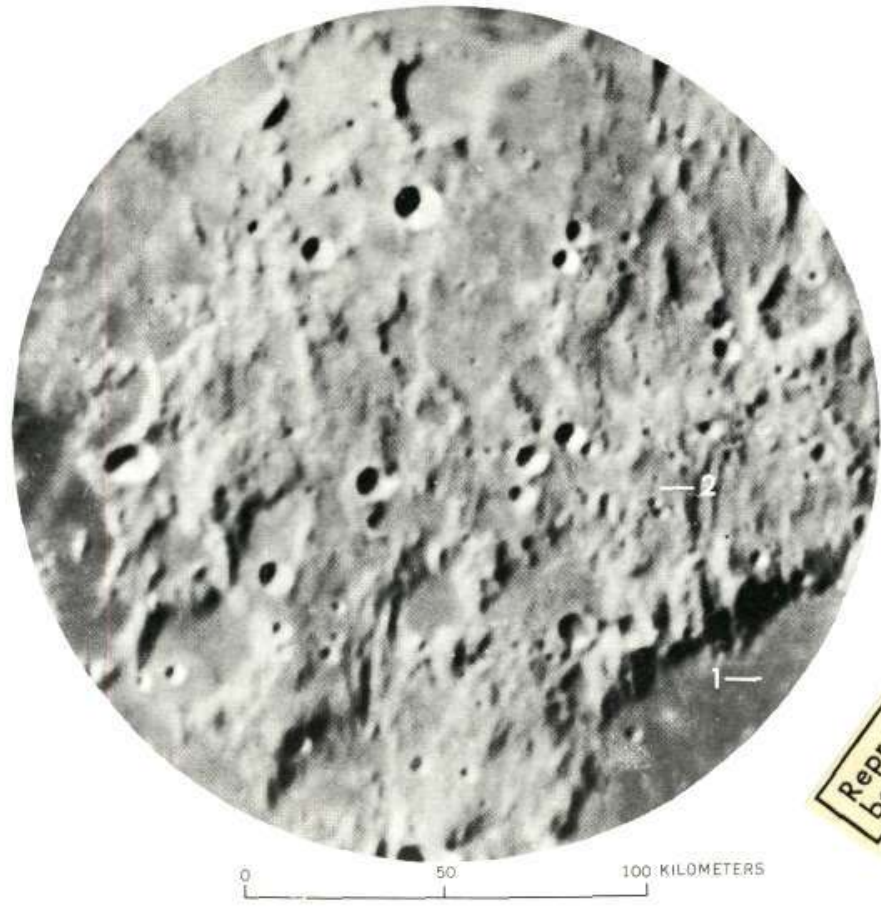

FIGURE 27.-Representative lunar terrain units in Apennine Mountains, south of Mare Imbrium (lat $25^{\circ} \mathrm{N}$., long $3^{\circ}$ E.; Lick Observatory plate ECD 35 ).

Unit I-B. Dark mare (1).

Unit II-D. Rough high blocky terra (2). Side slopes about $20^{\circ}$ and relief of $3,000-4,000$ meters.

Unit IV-C-2. Sinuous rille (3); steep interior slopes, flat floor.

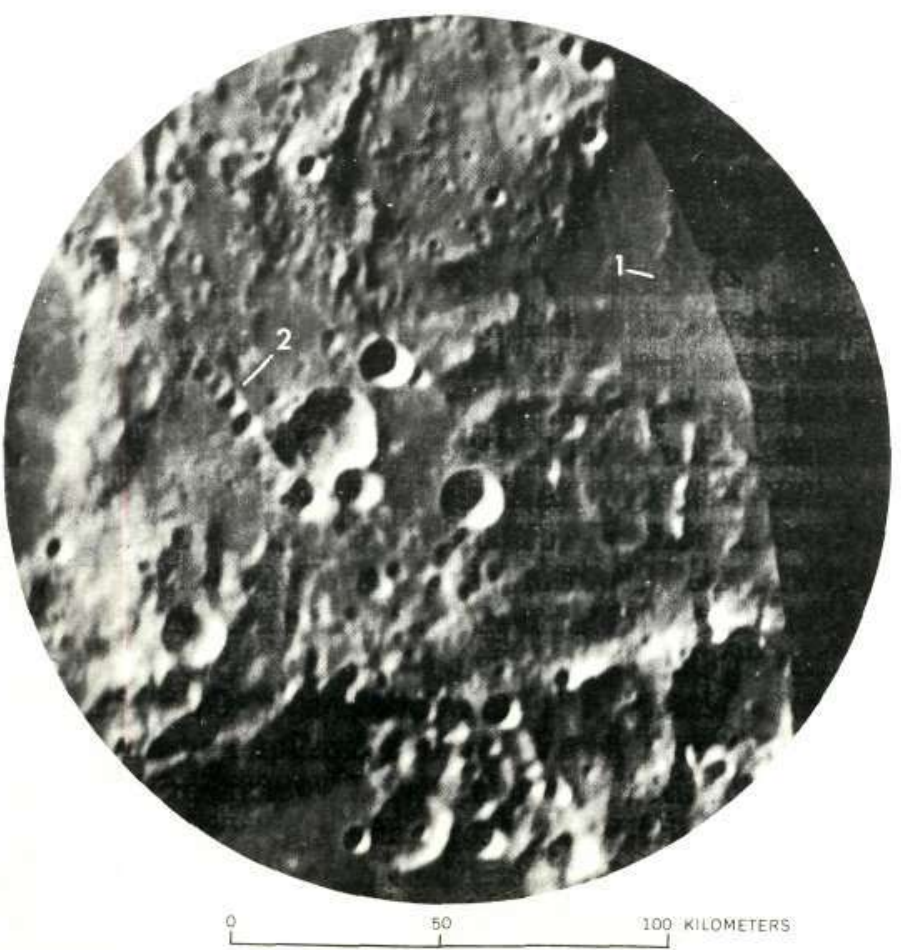

4 FIgURE 26.- Representative lunar terrain units in area northeast of crater Ptolemaeus (lat $7^{\circ} \mathrm{S}$., long $6^{\circ} \mathrm{W}$.; Lick Observatory plate ECD 65) :

Unit II-A. Terra plains (1) ; gently rolling in places. Unit II-C. Hummocky to blocky, lineated terra (2).
4 Figure 25.-Representative lunar terrain units in area between craters Ptolemaeus and Hipparchus (lat 7.5 $\mathrm{S}$., long $3^{\circ} \mathrm{E}$.; Lick Observatory plate ECD 65 ) :

Unit II-A. Terra plains (1).

Unit IV-1-1. Chain craters (2); coalescing craters with low smooth rims located along a linear structure. 


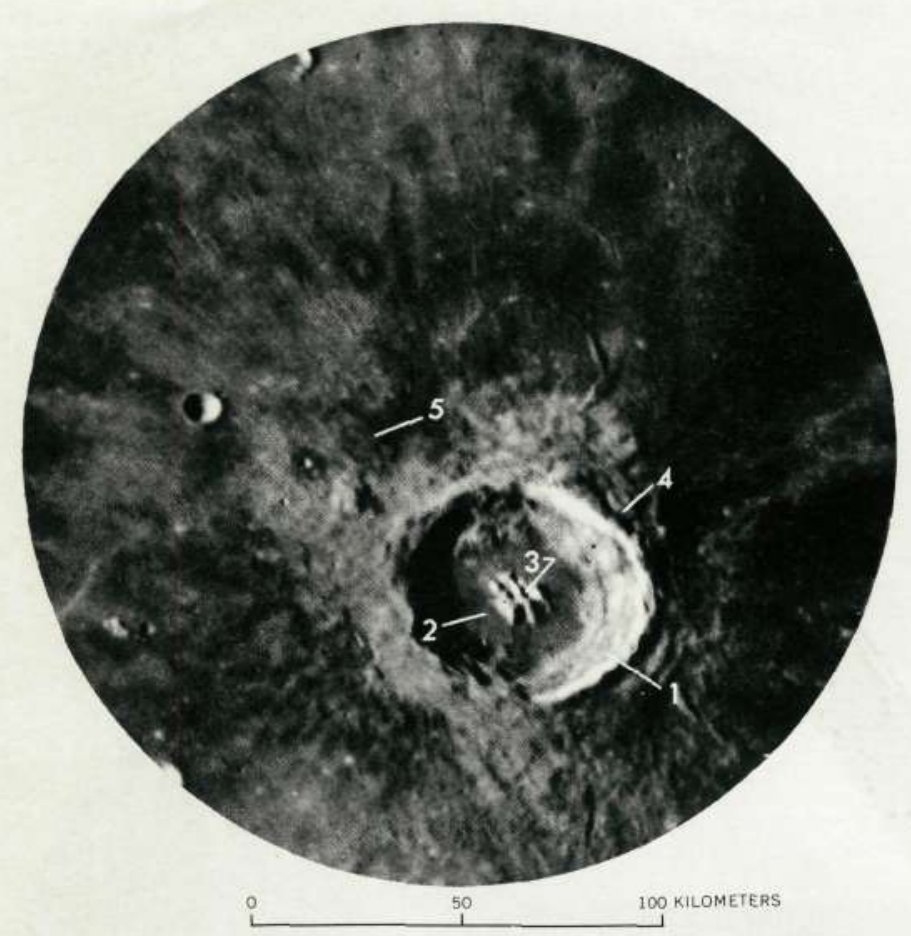

4 Figure 28.-Representative lunar terrain units in Aristillus area in Mare Imbrium (lat $35^{\circ} \mathrm{N}$., long $0^{\circ}$ E.; Lick Observatory plate ECD 35 ) :

Unit III-A-1a. Steeply sloping, terraced inner crater wall (1) ; slopes up to $30^{\circ}$.

Unit III-A-2a. Smooth crater floor (2).

Unit III-A-2c. Crater central peaks (3) ; rough blocky slopes up to $20^{\circ}$.

Unit III-A-3a. Rough terraced crater rim (4); slopes up to $15^{\circ}$; extends outward for about one-half of the crater diameter.

Unit III-A-3b. Radial ridge terrain on crater rim; extends outward for about one crater diameter (5); markedly smoother than unit III-A-3a.

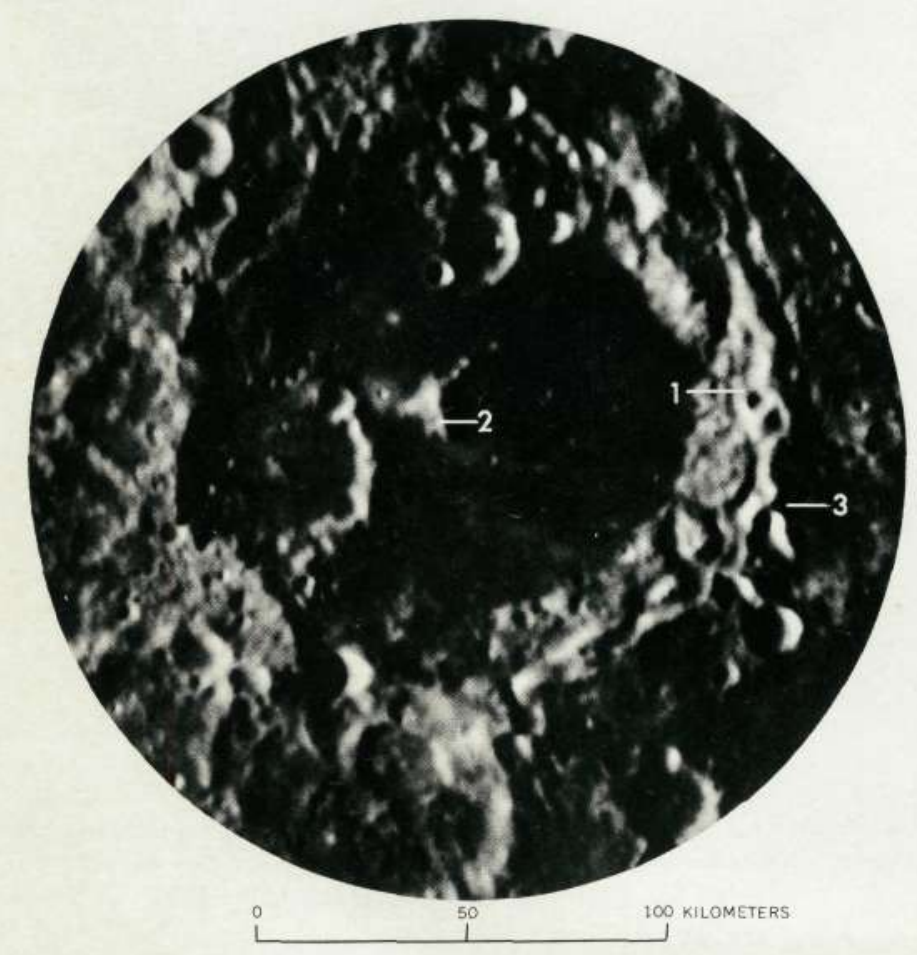

- Figure 29.-Representative lunar terrain units in Albategnius area (lat $12^{\circ} \mathrm{S}$., long $4^{\circ}$ E.; Lick Observatory plate ECD 18):

Unit III-B-1. Subdued or modified crater wall (1); slopes about $10^{\circ}$; smooth terraces.

Unit III-B-2c. Subdued crater central peaks (2); smoother and of lower relief than peaks in unmodified large craters.

Unit III-B-3. Rolling, gently terraced to hummocky terrain on crater rim (3); traceable outward for onequarter to one-half of the rim diameter. 